\title{
Safety assessment of hydro-generating units using experiments and grey-entropy correlation analysis
}

\author{
Huanhuan $\mathrm{Li}^{1,2}$, Diyi Chen ${ }^{1,2^{*}}$, Ehsan Arzaghi ${ }^{3}$, Rouzbeh Abbassi ${ }^{4}$, Beibei Xu ${ }^{1,2}$, Edoardo \\ Patelli ${ }^{5}$, Silvia Tolo ${ }^{5}$ \\ ${ }^{1}$ Key Laboratory of Agricultural Soil and Water Engineering in Arid and Semiarid Areas, \\ Ministry of Education, Northwest A\&F University, Shaanxi Yangling 712100, P. R. China \\ ${ }^{2}$ Institute of Water Resources and Hydropower Research, Northwest A\&F University, \\ Shaanxi Yangling 712100, P. R. China \\ ${ }^{3}$ Wind Energy Research Group, Delft University of Technology, Delft 2629HS, \\ Netherlands \\ ${ }^{4}$ School of Engineering, Faculty of Science and Engineering, Macquarie University, \\ Sydney, NSW, Australia \\ ${ }^{5}$ Institute for Risk and Uncertainty, University of Liverpool, Peach Street, Chadwick \\ Building, Liverpool L69 7ZF, United Kingdom
}

\section{Corresponding author: Diyi Chen}

Telephone: 086-181-6198-0277

E-mail: diyichen@nwsuaf.edu.cn

Abstract: This paper focuses on the safety analysis of a nonlinear hydro-generating unit

(HGU) running under different loads. For this purpose, a dynamic balance experiment implemented on an existing hydropower station in China is considered, to qualitatively investigate the stability of the system and to obtain the necessary indices for safety assessment. The experimental data are collected from four on-load units operating at different working heads including 431m, 434m, 437m, and 440m. A quantitative analysis on the safety performance of the four units was carried out by employing an integration of entropy weights method with grey correlation analysis. This assisted in obtaining the safety degree of each unit, providing the risk prompt to the operation of nonlinear 
hydro-generating units. The results confirm that unit 4 has the highest level of safety while unit 3 operates with the lowest safety condition. This provides the optimal operational schedule of HGUs to cope with the fluctuations of electricity demand in the studied station. The proposed methodology in this paper is not only applicable to the HGUs in the studied station but could also be adopted to assess the safety degree of any hydropower facility.

Keywords: hydro-generating unit; dynamic balance experiment; safety analysis; grey-entropy correlation;

\section{Introduction}

Renewable energy is unarguably one of the most critical governing factors for today's increasing global economic and social development [1]. The pressing challenge lies in the sustainable harnessing of reliable, secure and affordable energy [2]. To date, hydropower has been the main renewable source of electrical energy for many countries' power consumption (e.g. 99\% in Norway, $86 \%$ in Brazil and $76 \%$ in Switzerland) due to the environmental consequences of fossil fuels exploitation [3]. The electricity provided by hydropower contributes about $16 \%$ of the world total electricity generation and is expected to grow to $2 \mathrm{GW}$ in thirty years [4]. It is therefore no exaggeration that hydropower represents more than $92 \%$ of generated green energy making it a significant contributor to the global electricity supply [5].

Hydropower stations are the major electricity generation facilities in which the hydro-generating unit (HGU) is the heart of the energy production, transmission and 
conversion in each station [6]. HGU is a complex nonlinear system that integrates the characteristics of fluid, machinery, and electromagnetic induction [7]. A universal HGU is comprised of various coupled components such as hydraulic turbines, shafting systems, generators, governors, and excitation systems ([8] to [12]).

Due to the nonlinear coupled characteristics, several hazardous factors are present within the operation of an HGU including shafting vibrations, electromechanical delays, stochastic instability, and inefficient operation. A large number of literatures have extensively studied such topics from the perspective of individual subcomponents, which supports the research foundation for the safety study in this paper. For instance, literatures ([13], [14]) analyzed the cause of shafting vibrations in an HGU. Literature [15] studied a class of hydro-turbine with electromechanical delays. Researchers in ([16], [17]) modelled stochastic variables of an HGU to analyze its effect on the stability of subcomponents. Researchers in ([18], [19]) studied the adaptation strategy of hydropower systems to improve the operating efficiency. This range of conducted research highlights that the hydropower industry is greatly concerned about the safety of HGU operations and improvements are needed [20]. In particular, with the construction of large-capacity hydropower stations to be completed in the following decades, resolving the stability problems of operation, from the perspective of systemic properties, will be one of the major areas that attracts a great deal of attention from the industry [21]. Although a large number of advanced safety assessment methods have been developed in various research fields such as information science [22], ecological engineering [23] and marine engineering [24, 
$7125]$, the operational safety of HGUs has been rarely investigated and very little evidence of

72 achievements has been previously provided.

To date, the safety analyses of HGUs have mainly focused on investigating the

74 stability of HGU components. The developed methods determine the instability status of

75 the HGU components in terms of narrow hydraulic, mechanical, or electrical angle.

76 However, the integrated safety level of the entire HGU system has not been evaluated from

77 these independent components. Hence, there is a need for a framework that can assess the

78 safety of HGU from the system perspective. Previous researches ([26] to [30]) developed a

79 framework, combining the method of entropy weights and grey correlation theory to

80 investigate the quality problems in different applications such as wastewater treatment, soil

81 detection, and machinery fault. Several studies ([31], [32], and [33]) indicate that the

82 method of entropy weights has a great potential for the assessment of complex systems by

83 measuring the uncertainties of structure indices. The outcome of researches ([34], [35], and

84 [36]) reveal that the grey correlation theory can be adopted for various prediction

85 applications of such complex systems based on incomplete information.

The present paper herein investigates the operational stability of a nonlinear HGU

87 and proposes a methodology for safety assessment of these systems. For this purpose, a

88 dynamic balance experiment is conducted on four HGU units, each with a different

89 working head, in an existing hydropower station in China. The experiment is based on

90 vibration parameter, which is the main risk factor of on-load HGUs. Seventeen indices

91 are extracted to qualitatively assess the operational stability of the units. An effective 

approach integrating the entropy theory and grey correlation is then utilized to quantitatively analyze the safety performance of the studied HGU. This assisted in determining the safety degree of the analyzed four units that run with load, as well as an optimal operational schedule of HGUs coping with peaks and troughs of electricity demand in the studied hydropower station.

The present paper has extensively reviewed the existing literature that are based on the individual subcomponents (e.g. hydro-turbines, shafts and generators) of HGU systems.

The major contribution of the paper, however, is to consider the coupled characteristics of hydraulic, mechanical and electrical subcomponents for investigating the safety of HGU operation. Moreover, there are few researches that have successfully applied dynamic safety assessment to nonlinear HGUs. This paper presents a novel methodology that is significantly more flexible and efficient in dynamic safety assessment of HGUs with an attempt to overcome the limitations of static approaches. The safety degree of HGUs is quantified by using a probabilistic approach, which serves as a tool for monitoring and predicting the risk of accidents in hydropower stations resulting from failure in HGUs. This not only improves the safety of HGU operation, but also effectively reduces the operational and maintenance costs of energy production. The results obtained from this research benefit the operators and risk managers of the hydropower industry serving as a tool for development of risk mitigation strategies. For instance, it enables them to respond to the important question of "how to efficiently and safely arrange the operation of multiple HGUs with respect to different allowing heads". 
114 universal nonlinear HGU is presented. In Section 3 the fundamentals of utilized methods

115 and an overview of the global methodology for safety assessment of HGU are provided.

116 Section 4 discusses the details of the conducted dynamic balance experiment on the

117 studied station's HGU. Section 5 demonstrates the process of safety assessment

118 methodology and presents its highlighted results. Lastly, the key findings of this study are

119 discussed in the conclusion section.

\section{2. A Brief Review of an on-load HGU}

HGU is the key equipment of hydropower stations used to produce, transmit and

123 converse electrical energy, which mainly consists of hydraulic turbines, generators,

124 control systems/governors, excitation systems and inlet and draft pipes [37]. The

125 operation of an HGU is always integrated with a number of other hydraulic components

126 such as surge tank, piping system, water gate and reservoir [38]. The structure of an HGU

127 and the key elements of the hydraulic system are shown in Fig. 1. 


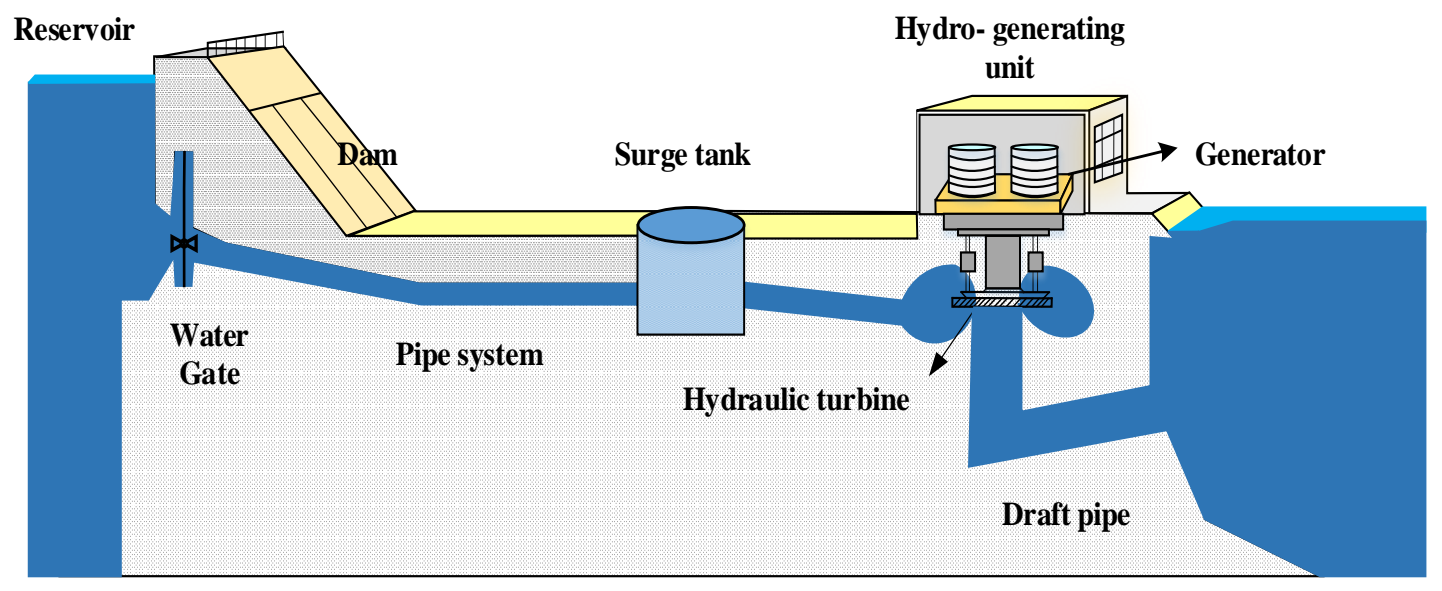

Fig. 1 Schematic of an HGU.

HGU, in fact, is a nonlinear system with multi-attribute characteristics including hydraulic, mechanical, electrical and electromagnetic. An on-load HGU is a system synchronized with the power grid, and its load generally cannot be constantly maintained due to the stochastic load. The on-load HGU may be considered as a dynamic system varying with the changes (decrease or increase) in load. An HGU mainly utilizes pressure and momentum energy to produce power. The working mechanism of an on-load HGU is described as the flow velocity influenced by the effect of blade changes as the system load fluctuates, which in turn generates a reactive force in the flow channel. This drives the hydraulic turbines which generate mechanical energy, and the generator further converts the mechanical energy to electrical energy. The details of an HGU working mechanism is presented in Fig. 2. 

experimental investigations.

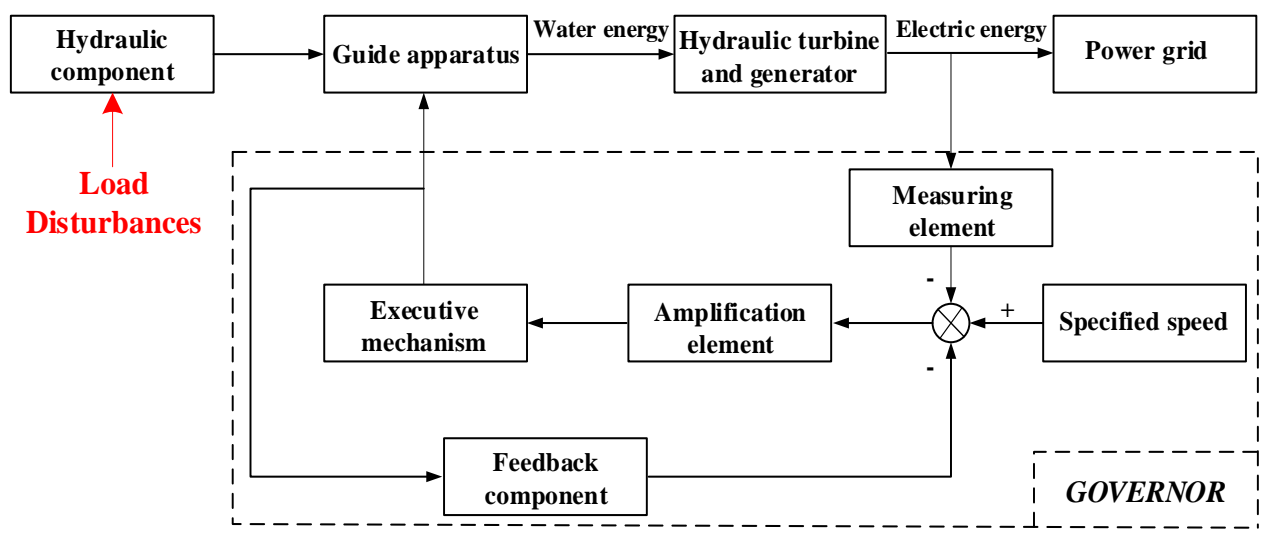

Fig. 2 Details of an on-load HGU working mechanism.

In actual hydropower stations, the dynamic performance of HGUs is hard to detect due to the rapid changes in the operational conditions influenced by internal couplings as well as the external environment. Uncontrolled and abrupt changes in the dynamic variables influencing the operational conditions of the system could result in critical damage to the asset as well as other consequences. It is therefore essential to conduct quantitative assessment of the safety and stability of an HGU, probably based on

\section{Methodology}

Previous researches in this field have focused on developing static safety assessment

153 frameworks for operating HGUs. However, due to the nonlinearity of these systems, 154 attending to the dynamic effects in the analysis are essential for achieving better results. To 155 overcome this shortcoming, an effective method must be developed applicable to 156 hydropower facilities. Through conducting an interdisciplinary research [26, 27], this 

safety assessment of an HGU, a specific index weight is the critical indicator to measure 177 the importance of the selected index, assessing its safety contribution to the studied

section presents the details of an enhanced grey-entropy correlation methodology for dynamic safety analysis of on-load HGUs. The proposed framework is able to improve the imprecision of subjective entropy weights as well as the static evaluation of grey correlation degrees. A major contribution of the established method is in adopting the probabilistic approaches to predict and reflect the real-time safety level of on-load HGUs, which is greatly beneficial when dealing in a timely manner with unexpected accidents and the development of improved safety and risk mitigation strategies.

\subsection{Entropy Weights Method}

The concept of entropy that is derived from thermodynamics theories represents a measure of disorder in a system. Entropy theory was proposed by Shannon, in 1948, to reflect the uncertainty in information science, it has been applied in various research fields for its precision and flexibility [39].

Two approaches can be applied for determining the weights of indices, known as subjective fixed weight and objective fixed weight methods. Entropy weight method, as an objective approach, is based on the amount of data, overcoming the subjectivity issues as it is independent of expert judgment. The main idea of entropy method is to determine the weights by index variations. In general, a smaller index weight represents a larger degree of index variation, meaning that the index may provide more assessment information and have significant influence on the stability of the system. In the entropy 
system.

179 Assuming that there are $m$ assessment indices and $n$ assessment units, the assessment 180 data is transformed into a form of standardization that employs a normalized method of 181 inverse index, shown in Eq. (1) [40].

$$
r_{i j}=\frac{\max x_{i j}-x_{i j}}{\max x_{i j}-\min x_{i j}}, i=1,2, \ldots, m \text { and } j=1,2, \ldots, n,
$$

where $\left\{\boldsymbol{r}_{i j}\right\}_{\boldsymbol{m} \times \boldsymbol{n}}$ is the normalized set of inverse index. $\max x_{i j}$ and $\min x_{i j}$ are the maximum and minimum values in the index column of assessment units, respectively. It should be noted that the lower value of inverse index is most important in ensuring safe operation of an HGU.

$$
E_{i}=-\frac{\sum_{j=1}^{n} r_{i j} \ln r_{i j}}{\ln n}, i=1,2, \ldots, m
$$

and the index weight of $i$ is obtained as:

$$
\omega_{i}=\frac{1-E_{i}}{\sum_{i=1}^{m}\left(1-E_{i}\right)}, \quad \sum_{j=1}^{n} \omega_{i}=1, \quad \omega_{i} \in[0,1]
$$

191 Therefore, the index weight set $\boldsymbol{W}_{i}$ is $\left[\omega_{1}, \omega_{2}, \ldots, \omega_{n}\right]$.

\subsection{Grey-entropy Correlation Method}

Grey system is used to describe an uncertain system that has the characteristic of

194 partial information loss, and grey correlation theory is a powerful tool to query the quality of a system with poor information [41]. An on-load HGU is an engineering system 
incorporating a degree of uncertainty and therefore it can be assessed by the grey

197 correlation theory. The concept of using grey theory is to find the possible motion rule

198 from the disordered and fuzzy data. Specifically, it is the similarity of an index in

199 different assessment units that is the key factor for measuring the variation between the

200 indices. A greater similarity between indices means that the grey correlation of a studied

201 unit is more optimal. There are no requirements for the size and characteristics of data in

202 a grey correlation analysis which overcomes the shortcomings of traditional regression

203 analyses.

204 Based on the normalized set of inverse index $\left\{\boldsymbol{r}_{i j}\right\}_{m \times n}$ mentioned in Eq. (1), the

205 index column is expressed as $\boldsymbol{x}_{1}, \boldsymbol{x}_{2}, \ldots, \boldsymbol{x}_{\boldsymbol{m}}$. It should be noted that, there are $i$ assessment

206 plans in the analysis, i.e., $\boldsymbol{x}_{i}=\left[x_{i}(1), x_{i}(2), \ldots, x_{i}(n)\right]$, where $\boldsymbol{x}_{0}$ is assumed to be the

207 optimum plan. Therefore, the correlation coefficient, $\boldsymbol{\xi}_{i}(j)$, between $\boldsymbol{x}_{0}$ and $\boldsymbol{x}_{i}$ with

208 respect to the $j^{\text {th }}$ factor in the index set $\left\{\boldsymbol{r}_{i j}\right\}_{m \times n}$ is expressed as [42]:

$$
\boldsymbol{\xi}_{i}(j)=\frac{\min _{i}\left(\Delta_{i} \min \right)+\rho \max _{i}\left(\Delta_{i} \max \right)}{\Delta_{i}+\rho \max _{i}\left(\Delta_{i} \max \right)}, i=1,2, \ldots, m \text { and } j=1,2, \ldots, n,
$$

210 where $\Delta_{i}$ is equal to $\left|x_{0}(j)-x_{i}(j)\right|, \rho$ is the resolution coefficient that changes

211 within the interval $[0,1]$, but generally it is set at $0.5 . \Delta_{i} \min$ and $\Delta_{i}$ max denote the

212 minimum and maximum differences in the first level respectively, while $\min _{i}\left(\Delta_{i} \min \right)$

213 and $\max _{i}\left(\Delta_{i} \max \right)$ are the minimum and maximum differences in the second level,

214 respectively. The expressions for each of these terms are shown as follows: 


$$
\left\{\begin{array}{l}
\Delta_{i} \min =\min _{j}\left|x_{0}(j)-x_{i}(j)\right| \\
\Delta_{i} \max =\max _{j}\left|x_{0}(j)-x_{i}(j)\right|
\end{array}\right.
$$

216 and

$$
\left\{\begin{array}{l}
\min _{i}\left(\Delta_{i} \min \right)=\min _{i} \min _{j}\left|x_{0}(j)-x_{i}(j)\right| \\
\max _{i}\left(\Delta_{i} \max \right)=\max _{i} \max _{j}\left|x_{0}(j)-x_{i}(j)\right|
\end{array},\right.
$$

219 the correlation coefficient $\xi_{i}(j)$ for the $i^{\text {th }}$ studied unit to obtain its integrating safety

220 degree. Therefore, the grey correlation degree, $\boldsymbol{\alpha}_{i}$, between the optimum unit and the 221 studied unit $i$ is given by the grey-entropy correlation equation as follows:

$$
\boldsymbol{\alpha}_{i}=\sum_{j=1}^{m} \boldsymbol{W}_{i} \boldsymbol{\xi}_{i}(j), \quad \mathbf{0} \leq \boldsymbol{\alpha}_{i} \leq \mathbf{1}
$$

In Eq. (7), the obtained grey correlation degree $\boldsymbol{\alpha}_{i}$, also defined as the safety degree,

224 assists in assessing the safety level of a multi-unit HGU from a probabilistic point of view.

225 That is, a higher value of $\boldsymbol{\alpha}_{i}$ corresponds to a safer HGU thus for instance, a system

226 with $\boldsymbol{\alpha}_{i}=\mathbf{1}$ has the maximum level of reliability.

\section{$227 \quad 3.3$ Global Methodology}

This paper presents a novel framework for the dynamic safety assessment of HGUs

229 by combining the entropy weight method with the grey correlation analysis. The major 230 novel components of the proposed method consist of:- firstly, the method overcomes the

231 subjectivity of traditional methods in determining the weight coefficients of assessment 232 indices, which improves the accuracy of the results and provides a more scientific 
representation. Secondly, the method completely transforms the static safety assessment into a dynamic practice by substituting the dynamic entropy weights (i.e. Eq. (3)) into the relationship for obtaining the grey correlation degree (i.e. Eq. (7)). Thirdly, few existing studies have been proven to be successful in conducting a probabilistic safety analysis of 237 nonlinear HGUs.

The steps of the developed methodology in this paper are provided in Fig. 3, and summarized as follows.

(1) A dynamic balance experiment is carried out on the existing HGUs for different allowing heads, to qualitatively analyze the dynamic operational behavior of a hydropower station. The obtained data, $m$ assessment indices for $n$ studied HGUs, is later used to 243 conduct a quantitative safety analysis.

(2) Dynamic entropy weights (see Eq. (3)) are developed to estimate the contribution

245 of the indices on HGSs' stability with respect to time. For this purpose, the indices with significant influence on HGS' operation under various allowing heads are identified.

(3) The grey-entropy correlation degrees (see Eq. (7)), combined with the dynamic 248 entropy weights (see Eq. (3)) and grey correlation coefficients (see Eq. (4)), are used to 249 evaluate the safety degree of $n$ studied HGUs. The safety degree is expressed by 250 probability values.

(4) Based on the quantitative analysis, the time-varying safety state of HGUs and any accidents are revealed. This enables the technicians and operators of hydropower stations 253 to make an optimal operational schedule of HGUs for dealing with fluctuations of 
254 electricity generation and demand.

255 A detailed illustration of the numerical process of entropy weights and safety

256 degrees is presented in the Appendix.

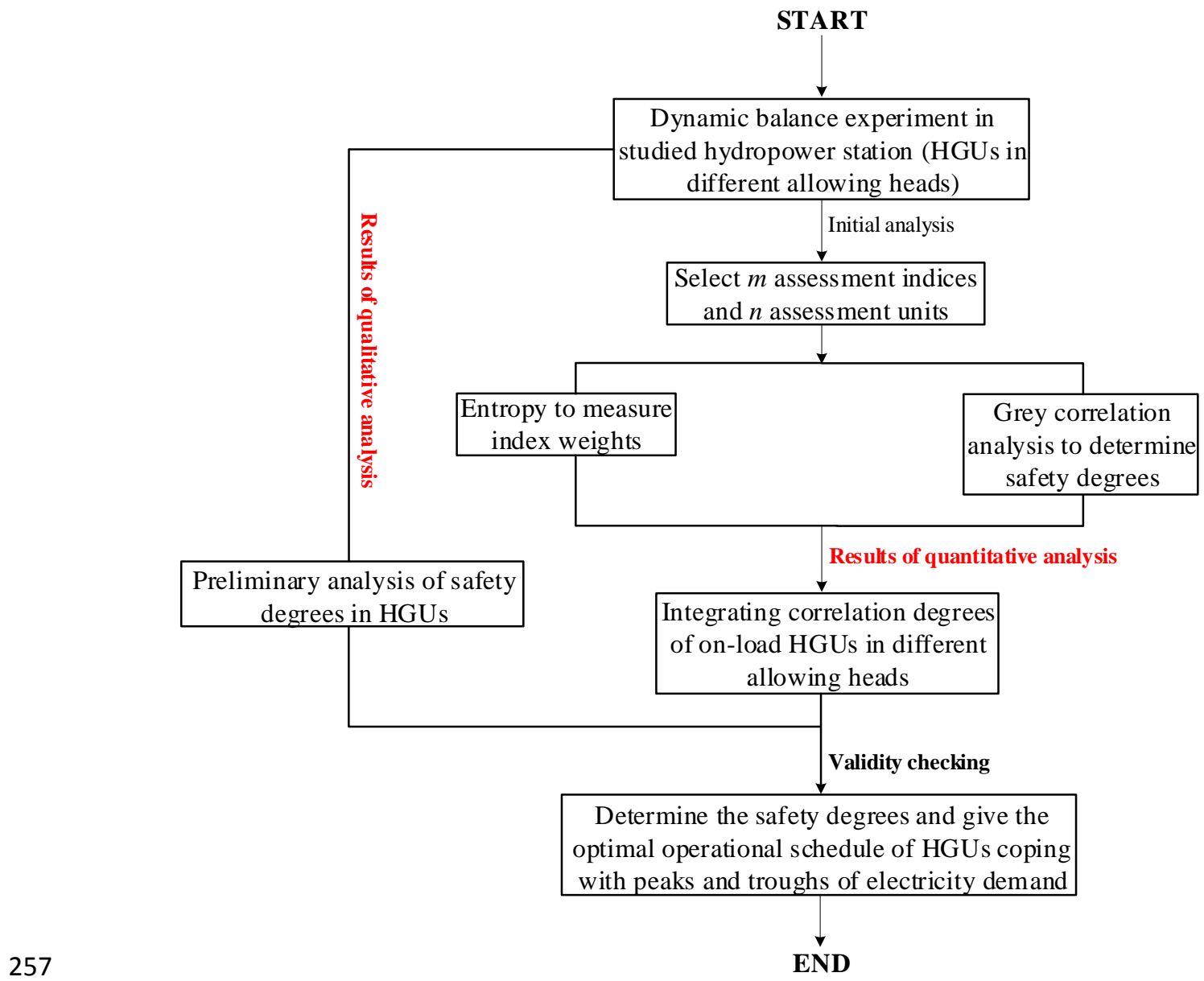

Fig. 3 Proposed framework for safety assessment of on-load HGUs.

260 4. Dynamic Balance Experiment on HGUs

261 In order to conduct a safety analysis on the HGU with load, a dynamic balance

262 experiment was carried out on the HGU in an existing hydropower station in China and 263 seventeen critical safety indices (i.e. X1-X17) were determined. These indices could 
264 reflect the instability of the system with respect to vibrations and pressure pulsations in 265 units. There are four Francis HGUs at the studied station, with installed and unit capacity 266 of $1050 \mathrm{MW}$ and $262.5 \mathrm{MW}$, respectively. In this experiment, the utilized sensors and 267 measurement equipment for vibration analysis include: the PSTA-H vibration 268 instrumentation of HGU, the TTS216 dynamic signal instrumentation of HGU, a CWY 269 eddy current displacement sensor, a DP low-frequency vibration sensor, a KYB pressure 270 transmitter and shielded signal cables. Some of the technical details of the four HGUs

271 tested in the experiment are listed in Table 1, and the arrangements of the monitoring 272 points on the HGUs, as well as the type of acquired data at each point, are presented in 273 Fig. 4.

274 Table 1 Information of the Francis hydraulic turbine of four HGUs in an existing 275 hydropower station.

\begin{tabular}{|c|c|c|c|}
\hline \multicolumn{4}{|c|}{ Information of Francis Hydraulic Turbines } \\
\hline Type & HLS270-LJ-680 & Nominal power & $267.85 \mathrm{MW}$ \\
\hline Nominal head & $64 \mathrm{~m}$ & Nominal flow & $460.46 \mathrm{~m}^{3} / \mathrm{s}$ \\
\hline Nominal speed & $93.75 \mathrm{rpm}$ & Runaway speed & $185 \mathrm{rpm}$ \\
\hline $\begin{array}{l}\text { Number of runner } \\
\text { blades }\end{array}$ & 13 & $\begin{array}{l}\text { Number of movable } \\
\text { guide vanes }\end{array}$ & 24 \\
\hline \multicolumn{4}{|c|}{ Information of Generators } \\
\hline Type & SF265-64/15000 & Nominal capacity & 291.7MVA \\
\hline Stator voltage & $15750 \mathrm{~V}$ & Stator current & $10692 \mathrm{~A}$ \\
\hline Power factor & 0.9 & Exciting voltage & $350 \mathrm{~V}$ \\
\hline Exciting current & $1900 \mathrm{~A}$ & Nominal frequency & $50 \mathrm{~Hz}$ \\
\hline \multicolumn{4}{|c|}{ Information of Governors } \\
\hline Type & PFWT-200-6.3 & $\begin{array}{l}\text { Main configuration } \\
\text { diameter }\end{array}$ & $200 \mathrm{~mm}$ \\
\hline Operating oil pressure & $6.3 \mathrm{MPa}$ & Servomotor stroke & $780 \mathrm{~mm}$ \\
\hline $\begin{array}{l}\text { Lower guide bearing } \\
\text { clearance }\end{array}$ & $0.15 \sim 0.2 \mathrm{~mm}$ & $\begin{array}{l}\text { Upper guide bearing } \\
\text { clearance }\end{array}$ & $0.15 \sim 0.2 \mathrm{~mm}$ \\
\hline Water guide bearing & $0.2 \sim 0.25 \mathrm{~mm}$ & Cylinder diameter of & $640 \mathrm{~mm}$ \\
\hline
\end{tabular}




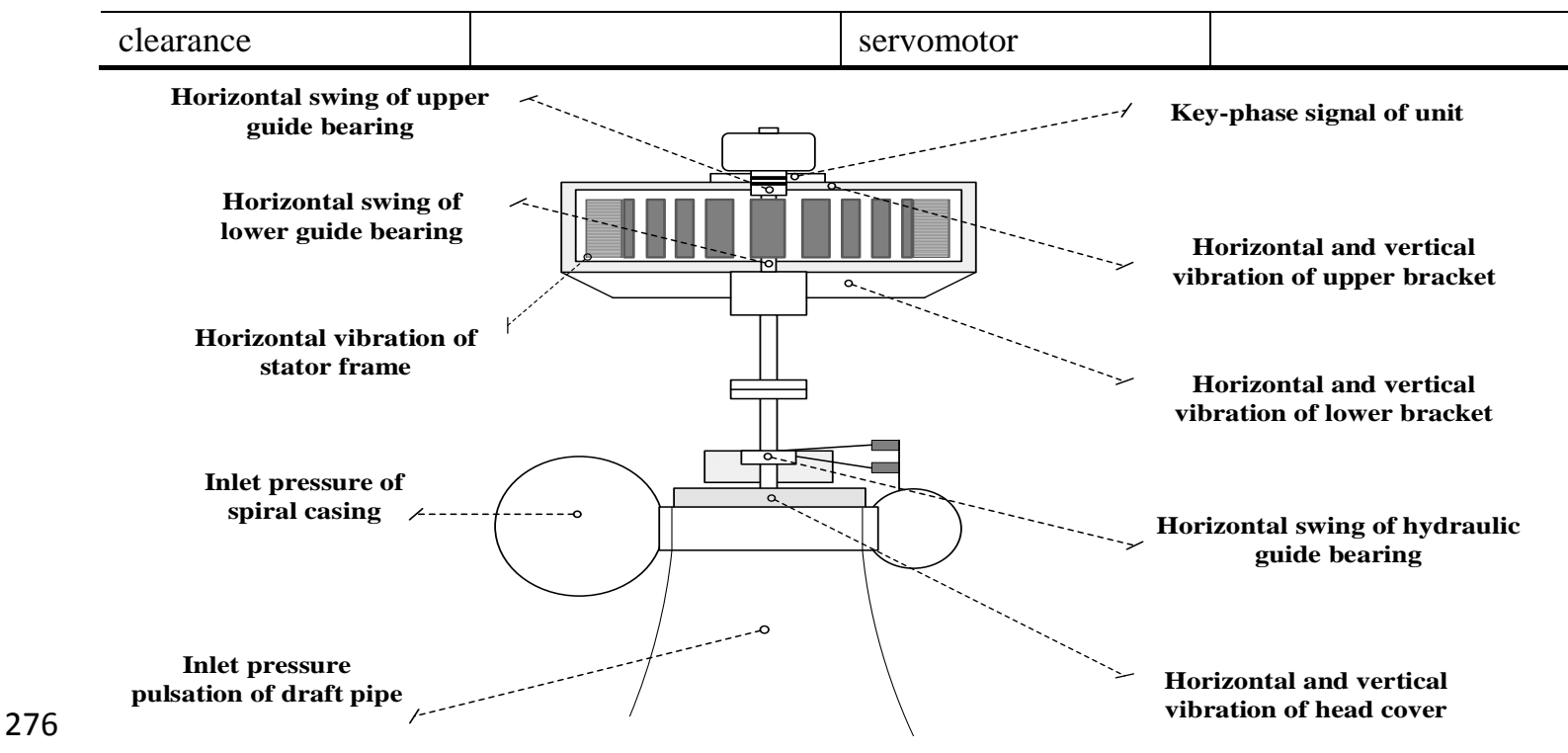

Fig. 4 Arrangements of monitoring points on HGU and type of recorded data at each point in

dynamic balance experiment in an existing hydropower station.

The initial running states of the four HGUs are different due to the internal coupled characteristics and external environment. A start-up test and a turbine-speed test are carried out for different HGUs before the dynamic balance experiments. This results in identifying the initial running state of the four HGUs, including that the rotating and fixed components for HGUs 1 and 4 operate normally and their vibration and swing values meet the design requirements. For HGUs 2 and 3, the start-up test shows that the rotating and fixed components run without abnormal friction or collision. Based on the turbine speed test at nominal speed for HGU 2, it is found that the horizontal vibration of upper 287 bracket $(290 \mu \mathrm{m})$, vertical vibration of upper bracket $(157 \mu \mathrm{m})$, swing of upper guide 288 bearing $(335 \mu \mathrm{m})$, swing of lower guide bearing $(417 \mu \mathrm{m})$ and swing of hydraulic guide bearing $(382 \mu \mathrm{m})$ exceed the design requirements. Similarly for HGU 3, the horizontal 
vibration of upper bracket $(203 \mu \mathrm{m})$ and swing of hydraulic guide bearing $(657 \mu \mathrm{m})$

exceed the design requirements. Moreover, the actual operating conditions for four HGUs Table 2.

Table 2 Actual operating conditions for four HGUs with different allowable heads $(431 \mathrm{~m}$, $434 \mathrm{~m}, 437 \mathrm{~m}$ and $440 \mathrm{~m}$ ) used in the dynamic balance experiment.

\section{HGU 1}

\begin{tabular}{l|c|c|c}
\hline \multicolumn{2}{c}{ Actual upstream head } & Actual downstream head & Actual head of station \\
\hline $431 \mathrm{~m} \mathrm{Head}$ & $431.71 \mathrm{~m}$ & $366.64 \mathrm{~m}$ & $65.07 \mathrm{~m}$ \\
\hline $434 \mathrm{~m} \mathrm{Head}$ & $433.60 \mathrm{~m}$ & $366.36 \mathrm{~m}$ & $67.24 \mathrm{~m}$ \\
\hline $437 \mathrm{~m} \mathrm{Head}$ & $436.40 \mathrm{~m}$ & $366.24 \mathrm{~m}$ & $70.16 \mathrm{~m}$ \\
\hline $440 \mathrm{~m} \mathrm{Head}$ & $439.40 \mathrm{~m}$ & $367.98 \mathrm{~m}$ & $71.42 \mathrm{~m}$ \\
\hline
\end{tabular}

HGU 2

\begin{tabular}{l|c|c|c}
\hline \multicolumn{2}{c}{ Actual upstream head } & Actual downstream head & Actual head of station \\
\hline $431 \mathrm{~m} \mathrm{Head}$ & $431.92 \mathrm{~m}$ & $366.11 \mathrm{~m}$ & $65.81 \mathrm{~m}$ \\
\hline $434 \mathrm{~m}$ head & $433.23 \mathrm{~m}$ & $365.62 \mathrm{~m}$ & $67.61 \mathrm{~m}$ \\
\hline $437 \mathrm{~m} \mathrm{head}$ & $437.33 \mathrm{~m}$ & $367.16 \mathrm{~m}$ & 70.17 \\
\hline $440 \mathrm{~m}$ head & $439.60 \mathrm{~m}$ & $368.29 \mathrm{~m}$ & $71.31 \mathrm{~m}$ \\
\hline \multicolumn{4}{c}{ HGU 3 }
\end{tabular}

\begin{tabular}{l|c|c|c}
\hline \multicolumn{2}{c}{ Actual upstream head } & Actual downstream head & Actual head of station \\
\hline $431 \mathrm{~m}$ head & $431.93 \mathrm{~m}$ & $367.19 \mathrm{~m}$ & $64.74 \mathrm{~m}$ \\
\hline $434 \mathrm{~m}$ head & $433.14 \mathrm{~m}$ & $366.27 \mathrm{~m}$ & $66.87 \mathrm{~m}$ \\
\hline $437 \mathrm{~m}$ head & $437.14 \mathrm{~m}$ & $367.48 \mathrm{~m}$ & $69.66 \mathrm{~m}$ \\
\hline $440 \mathrm{~m}$ head & $439.96 \mathrm{~m}$ & $367.87 \mathrm{~m}$ & $72.09 \mathrm{~m}$ \\
\hline
\end{tabular}

HGU 4

\begin{tabular}{l|c|c|c}
\hline \multicolumn{2}{c}{ Actual upstream head } & Actual downstream head & Actual head of station \\
\hline $431 \mathrm{~m}$ head & $432.66 \mathrm{~m}$ & $367.38 \mathrm{~m}$ & $65.28 \mathrm{~m}$ \\
\hline $434 \mathrm{~m}$ head & $433.31 \mathrm{~m}$ & $365.92 \mathrm{~m}$ & $67.39 \mathrm{~m}$ \\
\hline $437 \mathrm{~m} \mathrm{head}$ & $437.87 \mathrm{~m}$ & $367.97 \mathrm{~m}$ & $69.90 \mathrm{~m}$ \\
\hline $440 \mathrm{~m}$ head & $439.60 \mathrm{~m}$ & $367.67 \mathrm{~m}$ & $71.93 \mathrm{~m}$ \\
\hline
\end{tabular}

297 station varies within the range of $431 \mathrm{~m}$ to $440 \mathrm{~m}$. Four typical allowable heads (i.e. $431 \mathrm{~m}$,

$298434 \mathrm{~m}, 437 \mathrm{~m}$ and 440m) were chosen to conduct the dynamic balance experiment, where 
299 vibration, swing and water pressure were measured. Based on the requirement of the actual 300 operation in this station, the measurements were taken for various on-load conditions 301 within the load range of $120 \mathrm{MW}$ to $265.2 \mathrm{MW}$. The necessary indices in this experiment 302 were selected to qualitatively investigate the stability of four HGUs, and the results are 303 shown in Figs. 5 to 8.

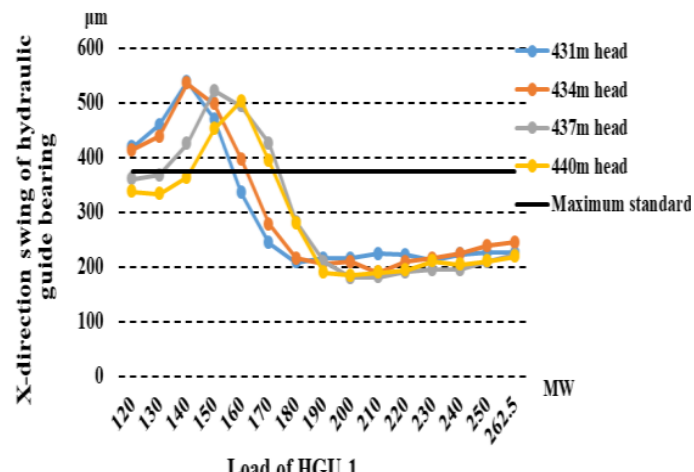

(a)

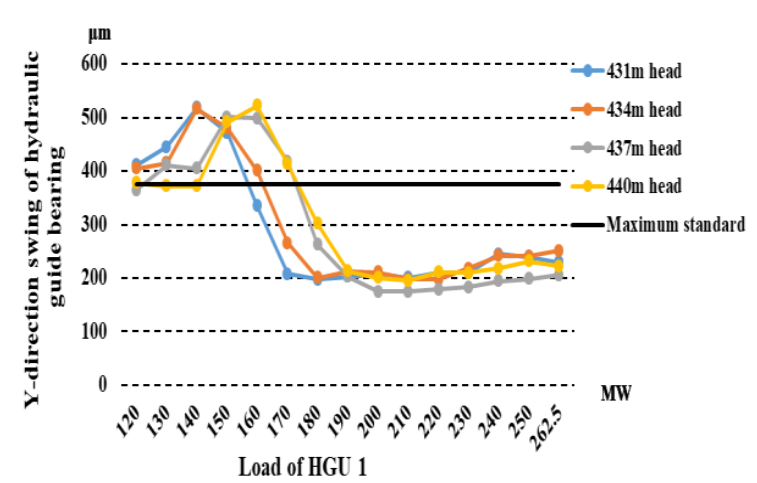

(b)

Fig. 5 Measurements of vibration property in dynamic balance experiment of HGU 1 at an

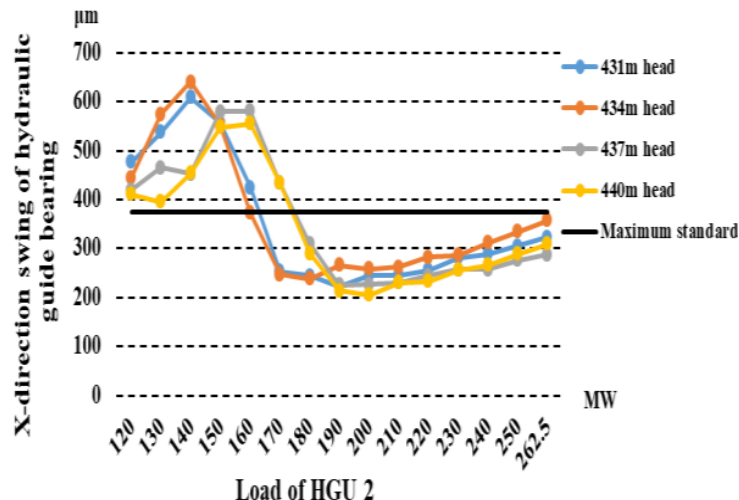

(a)

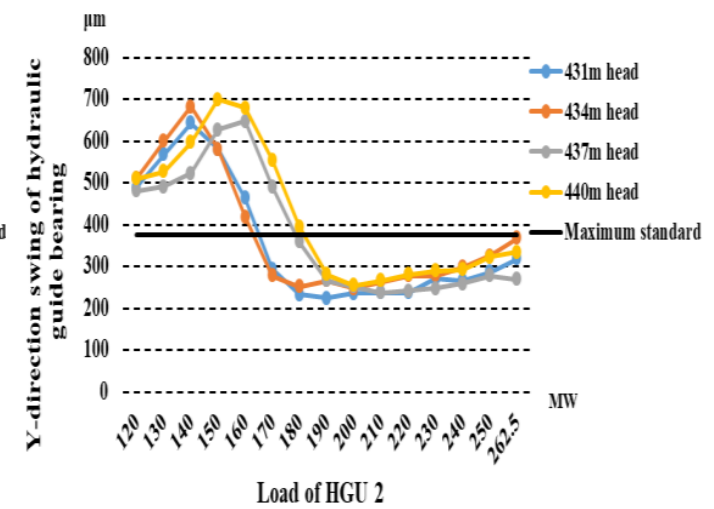

(b) 


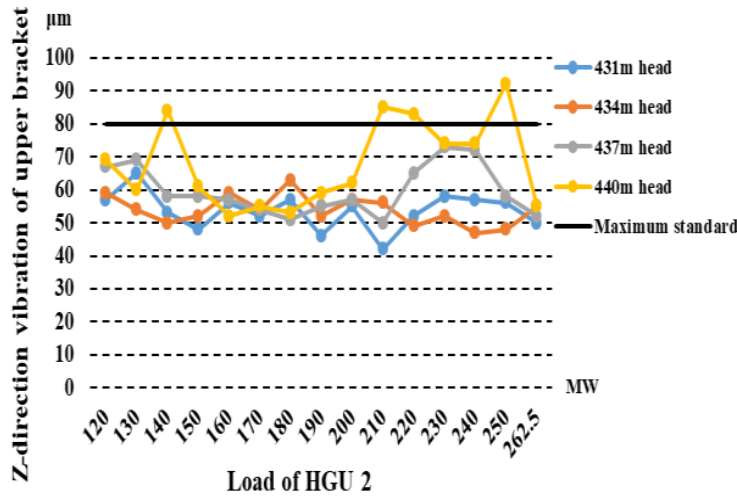

(c)

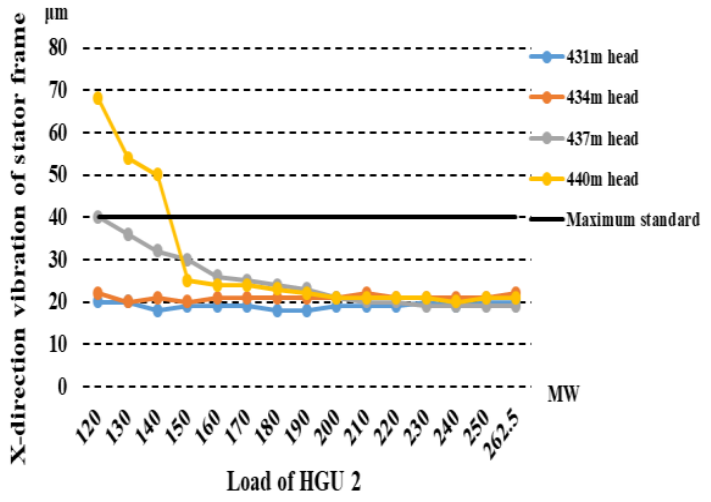

(d)

312 Fig. 6 Measurements of vibration property in dynamic balance experiment of HGU 2 at an existing hydropower station, China.

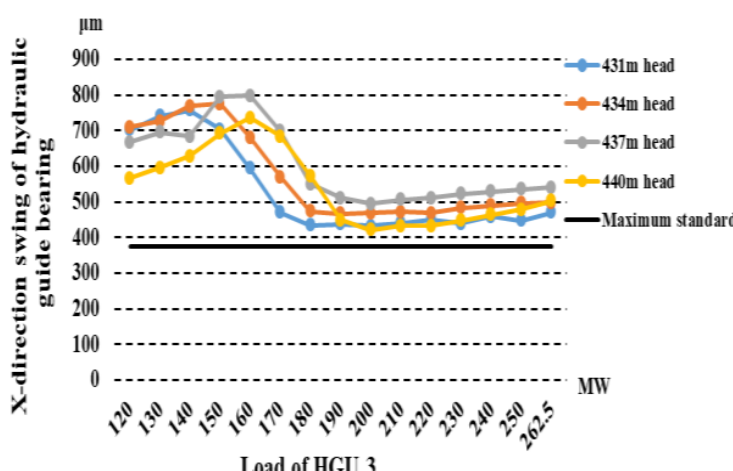

(a)

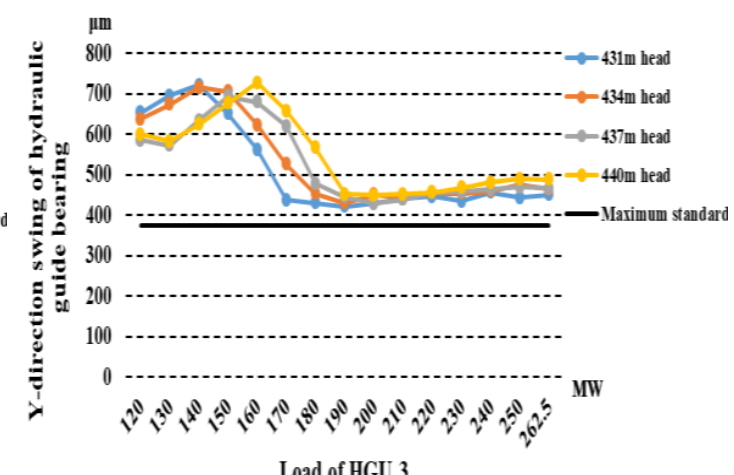

(b)

316 Fig. 7 Measurements of vibration property in dynamic balance experiment of HGU 3 at an existing hydropower station, China.

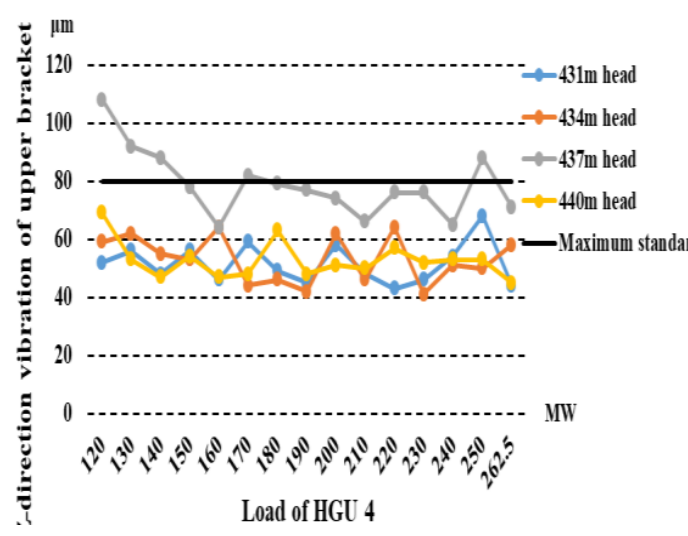

(a)

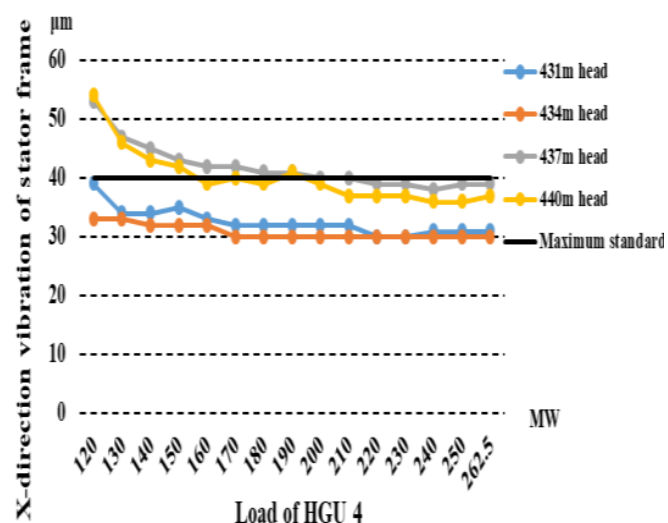

(b)

Fig. 8 Measurements of vibration property in dynamic balance experiment of HGU 4 at an existing hydropower station, China. 
44]. The allowable range for all indices (X1-X17) are listed in Table 3.

Table 3 Allowable ranges of HGU's indices (X1-X17) for safety operation from the national standards $[43,44]$.

\begin{tabular}{|c|c|c|c|}
\hline Index (X1-X9) & $\begin{array}{c}\text { Allowable } \\
\text { range }\end{array}$ & Index (X10-X17) & $\begin{array}{c}\text { Allowable } \\
\text { range }\end{array}$ \\
\hline $\begin{array}{l}\text { Inlet pressure pulsation of draft } \\
\text { pipe (X1) }\end{array}$ & $0 \sim 64 \mathrm{kPa}$ & $\begin{array}{l}\text { Z-direction vertical vibration of } \\
\text { upper bracket (X10) }\end{array}$ & $0 \sim 80 \mu \mathrm{m}$ \\
\hline $\begin{array}{l}\text { X-direction swing of upper } \\
\text { guide bearing }(\mathrm{X} 2)\end{array}$ & $0 \sim 300 \mu \mathrm{m}$ & $\begin{array}{l}\text { X-direction horizontal vibration } \\
\text { of lower bracket (X11) }\end{array}$ & $0 \sim 110 \mu \mathrm{m}$ \\
\hline $\begin{array}{l}\text { Y-direction swing of upper } \\
\text { guide bearing (X3) }\end{array}$ & $0 \sim 300 \mu \mathrm{m}$ & $\begin{array}{l}\text { Y-direction horizontal vibration } \\
\text { of lower bracket (X12) }\end{array}$ & $0 \sim 110 \mu \mathrm{m}$ \\
\hline $\begin{array}{l}\mathrm{X} \text {-direction swing of lower } \\
\text { guide bearing }(\mathrm{X} 4)\end{array}$ & $0 \sim 300 \mu \mathrm{m}$ & $\begin{array}{l}\text { Z-direction vertical vibration of } \\
\text { lower bracket (X13) }\end{array}$ & $0 \sim 80 \mu \mathrm{m}$ \\
\hline $\begin{array}{l}\text { Y-direction swing of lower } \\
\text { guide bearing (X5) }\end{array}$ & $0 \sim 300 \mu \mathrm{m}$ & $\begin{array}{l}\text { X-direction vibration of stator } \\
\text { frame }(\mathrm{X} 14)\end{array}$ & $0 \sim 40 \mu \mathrm{m}$ \\
\hline $\begin{array}{l}\text { X-direction swing of hydraulic } \\
\text { guide bearing (X6) }\end{array}$ & $0 \sim 375 \mu \mathrm{m}$ & $\begin{array}{l}\text { X-direction horizontal vibration } \\
\text { of head cover (X15) }\end{array}$ & $0 \sim 90 \mu \mathrm{m}$ \\
\hline $\begin{array}{l}\text { Y-direction swing of hydraulic } \\
\text { guide bearing }(X 7)\end{array}$ & $0 \sim 375 \mu \mathrm{m}$ & $\begin{array}{l}\text { Y-direction horizontal vibration } \\
\text { of head cover (X16) }\end{array}$ & $0 \sim 90 \mu \mathrm{m}$ \\
\hline $\begin{array}{c}\text { X-direction horizontal } \\
\text { vibration of upper bracket (X8) }\end{array}$ & $0 \sim 110 \mu \mathrm{m}$ & $\begin{array}{l}\text { Z-direction vertical vibration of } \\
\text { head cover (X17) }\end{array}$ & $0 \sim 110 \mu \mathrm{m}$ \\
\hline $\begin{array}{l}\text { Y-direction horizontal vibration } \\
\text { of upper bracket (X9) }\end{array}$ & $0 \sim 110 \mu \mathrm{m}$ & & \\
\hline
\end{tabular}

As illustrated in Table 3 and Figs. 5 to 8, each HGU has a level exceeding the

328 allowable vibrations. Through a comparison of the results, it can be seen that the most

329 stable HGU is unit 4 with the minimum vibration in the upper bracket (along Z-direction)

330 and in its stator frame (along X-direction). It can be seen in Figs. 5 to 7, that the vibration

331 of units 1, 2 and 3 are caused by two indices, i.e. swing of the hydraulic guide bearing

332 along $\mathrm{X}$ and $\mathrm{Y}$ directions. However, it should be noted that the vibration magnitude of 
these units is different where $Y^{3}>Y^{2}>Y^{1}$ and $X^{3}>X^{2}>X^{1}$ (e.g. $Y^{3}$ and $X^{3}$ refer to the magnitude of vibration in unit 3 along $\mathrm{Y}$ and $\mathrm{X}$ directions, respectively). The results of qualitative analysis highlight that the lowest level of safety among the studied units at the studied station is for unit 4 , while unit 2 shows a more stable operation. Unit 1 has a higher safety level than unit 2, however, it does not provide an optimal condition. During the analysis of unit 3 responses, additional vibrations were observed in the upper bracket (along Z-direction) and the stator frame (along X-direction). Since it could not be determined, based on a qualitative assessment, to what extent the different indices affect the operational performance of the four HGUs, a rigorous quantitative analysis is required to investigate the safety condition of these four units.

\section{Analysis of HGUs}

In order to more effectively analyze the safety of the HGUs at the studied station, the grey correlation method is employed based on the results of dynamic balance experiments. For this purpose, maximum vibrations of the seventeen indices are firstly adopted from the experiment results, as listed in Table 4. The maximum vibration of selected index is considered as the assessment criteria in qualitative analysis, where the optimum level of safety is set as $0 \mu \mathrm{m}$ due to the characteristic of inverse indices. Results of the grey correlation analysis for the four units are presented in Figs. 9 and 10.

Table 4 Measured Data: Maximum vibrations of seventeen assessment indices for HGUs (1-4) at an existing hydropower station, China. 


\begin{tabular}{|c|c|c|c|c|c|c|c|c|}
\hline \multicolumn{5}{|c|}{$431 \mathrm{~m} \mathrm{Head}$} & \multicolumn{4}{|c|}{$434 \mathrm{~m} \mathrm{Head}$} \\
\hline Index & HGU 1 & HGU 2 & HGU 3 & HGU 4 & HGU 1 & HGU 2 & HGU 3 & HGU 4 \\
\hline $\mathrm{X} 1$ & 32.69 & 62.94 & 36.55 & 49.24 & 48.73 & 72.58 & 70.05 & 82.23 \\
\hline $\mathrm{X} 2$ & 162 & 205 & 176 & 229 & 161 & 205 & 185 & 233 \\
\hline $\mathrm{X} 3$ & 160 & 249 & 164 & 168 & 158 & 258 & 193 & 244 \\
\hline $\mathrm{X} 4$ & 289 & 245 & 178 & 230 & 306 & 233 & 180 & 237 \\
\hline $\mathrm{X} 5$ & 328 & 241 & 209 & 196 & 340 & 234 & 203 & 280 \\
\hline X6 & 539 & 608 & 757 & 258 & 536 & 640 & 775 & 324 \\
\hline $\mathrm{X} 7$ & 519 & 643 & 721 & 234 & 516 & 682 & 716 & 288 \\
\hline $\mathrm{X} 8$ & 63 & 68 & 56 & 67 & 70 & 60 & 72 & 74 \\
\hline $\mathrm{X} 9$ & 77 & 66 & 73 & 60 & 70 & 56 & 60 & 64 \\
\hline $\mathrm{X} 10$ & 59 & 65 & 64 & 56 & 61 & 63 & 56 & 64 \\
\hline X11 & 28 & 17 & 17 & 11 & 36 & 14 & 18 & 25 \\
\hline $\mathrm{X} 12$ & 30 & 11 & 17 & 14 & 25 & 13 & 21 & 29 \\
\hline $\mathrm{X} 13$ & 56 & 62 & 41 & 88 & 59 & 56 & 58 & 163 \\
\hline X14 & 20 & 20 & 17 & 39 & 19 & 22 & 17 & 33 \\
\hline $\mathrm{X} 15$ & 30 & 37 & 26 & 27 & 40 & 31 & 56 & 41 \\
\hline $\mathrm{X} 16$ & 20 & 16 & 17 & 19 & 25 & 24 & 26 & 27 \\
\hline $\mathrm{X} 17$ & 61 & 27 & 44 & 75 & 53 & 56 & 59 & 76 \\
\hline \multicolumn{9}{|c|}{ Maximum vibrations $(\mu \mathrm{m})$} \\
\hline \multicolumn{5}{|c|}{$437 \mathrm{~m} \mathrm{Head}$} & \multicolumn{4}{|c|}{ 440m Head } \\
\hline Index & HGU 1 & HGU 2 & HGU 3 & HGU 4 & HGU 1 & HGU 2 & HGU 3 & HGU 4 \\
\hline $\mathrm{X} 1$ & 69.89 & 61.19 & 95.52 & 79.04 & 86.67 & 168.14 & 121 & 46.39 \\
\hline $\mathrm{X} 2$ & 134 & 153 & 137 & 204 & 128 & 147 & 132 & 182 \\
\hline $\mathrm{X} 3$ & 141 & 195 & 151 & 214 & 151 & 210 & 162 & 201 \\
\hline $\mathrm{X} 4$ & 289 & 230 & 183 & 236 & 281 & 221 & 189 & 195 \\
\hline $\mathrm{X} 5$ & 252 & 186 & 131 & 237 & 289 & 157 & 180 & 178 \\
\hline $\mathrm{X} 6$ & 522 & 580 & 794 & 319 & 503 & 555 & 736 & 363 \\
\hline $\mathrm{X} 7$ & 501 & 648 & 694 & 290 & 523 & 700 & 727 & 365 \\
\hline $\mathrm{X} 8$ & 76 & 79 & 62 & 69 & 88 & 77 & 72 & 72 \\
\hline X9 & 92 & 70 & 67 & 106 & 98 & 96 & 64 & 71 \\
\hline $\mathrm{X} 10$ & 67 & 73 & 74 & 108 & 71 & 94 & 94 & 69 \\
\hline X11 & 25 & 97 & 82 & 29 & 26 & 19 & 25 & 25 \\
\hline $\mathrm{X} 12$ & 32 & 82 & 55 & 34 & 29 & 21 & 26 & 30 \\
\hline X13 & 76 & 15 & 255 & 115 & 68 & 108 & 185 & 102 \\
\hline X14 & 24 & 40 & 45 & 53 & 26 & 68 & 43 & 54 \\
\hline $\mathrm{X} 15$ & 82 & 63 & 107 & 48 & 63 & 94 & 61 & 66 \\
\hline X16 & 91 & 29 & 117 & 58 & 46 & 61 & 82 & 86 \\
\hline $\mathrm{X} 17$ & 92 & 79 & 306 & 90 & 81 & 109 & 140 & 74 \\
\hline
\end{tabular}




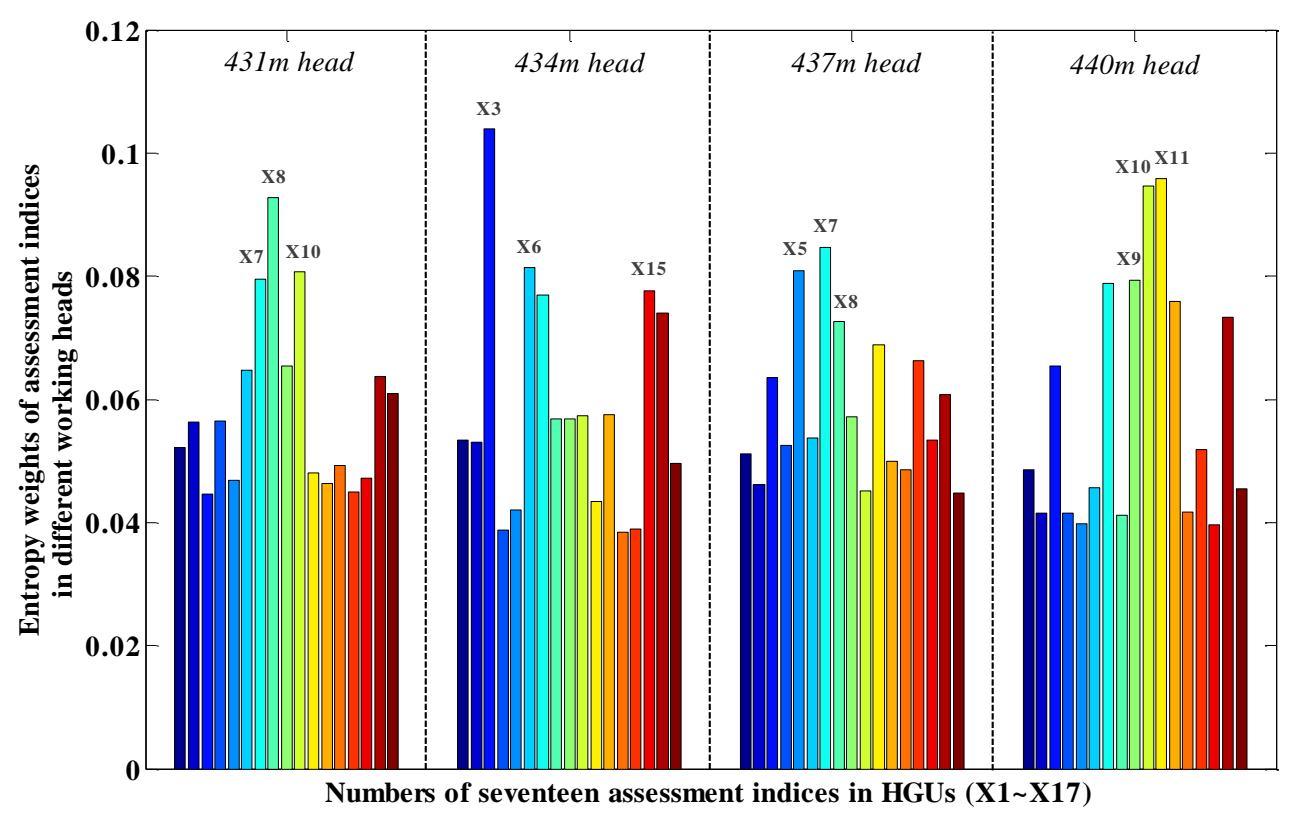

355 Fig. 9 Entropy weights of seventeen assessment indices for four on-load HGUs with different working heads
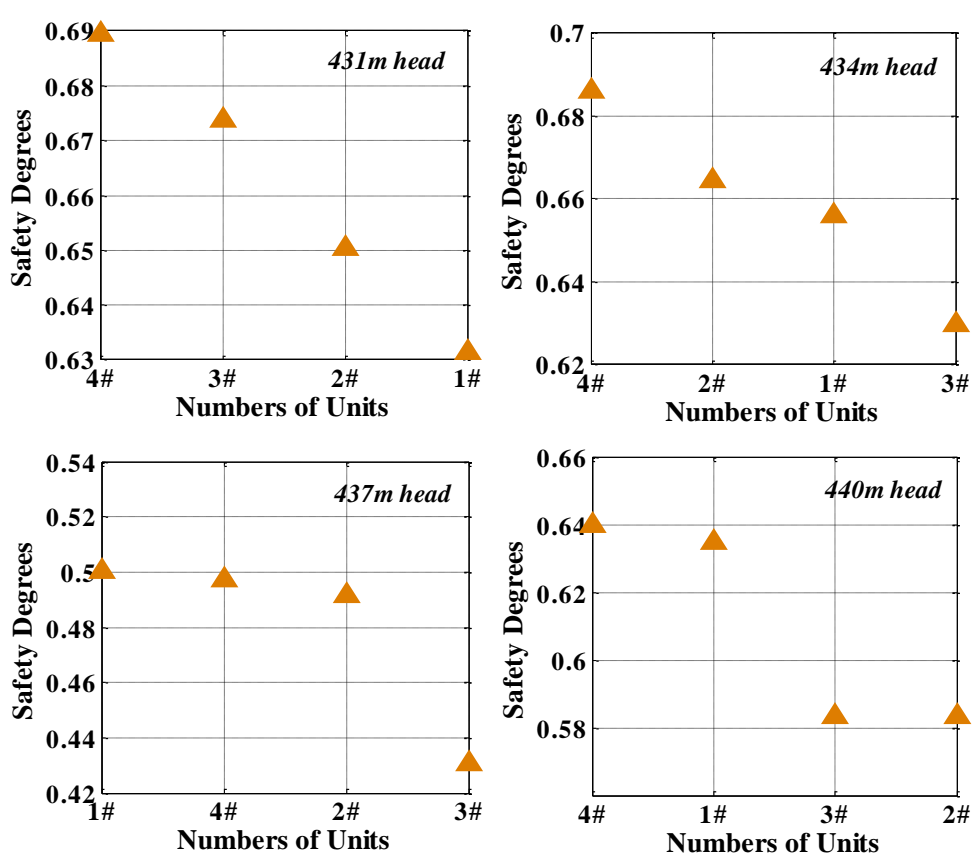

Fig. 10 Estimated safety levels of four on-load HGUs operating with different working heads at 
Fig. 9 indicates the assessment weights (i.e. the calculated entropy weights in Eq. (3))

361 of seventeen indices for HGUs operating with working heads of $431 \mathrm{~m}, 434 \mathrm{~m}, 437 \mathrm{~m}$ and

$362440 \mathrm{~m}$. It should be noted that the same index assessed in different allowable heads has

363 the same color. Considering Fig. 9, it is observed that the weight of each index differs

364 considerably as the allowable head changes. This confirms the sensitivity of assessment

365 indices on the HGUs' working heads as well as the fact that the information associated

366 with the indices for the studied units is not identical. For instance, the highest weights for

$367431 \mathrm{~m}$ working head are estimated as 0.093 for the horizontal vibration of upper bracket in

$368 \mathrm{X}$ direction (X8 index), 0.081 for the vibration of upper bracket in $\mathrm{Z}$ direction (X10 index)

369 and 0.08 for the swing of hydraulic guide bearing in Y direction (X7 index). Similarly, it

370 is found that for the HGU with $434 \mathrm{~m}$ working head, the main indices are X3, X6 and X15;

371 for the $437 \mathrm{~m}$ head unit, the main indices are X7, X5 and X8; and for the 440m head, they

372 are X11, X10 and X9. Based on the effect of main indices and experimental results, the

373 safety issues in the units with working heads of $431 \mathrm{~m}, 434 \mathrm{~m}$ and $437 \mathrm{~m}$ may be caused by

374 the integrating effect of mechanical problems and hydraulic imbalance while the

375 mechanical component only results in a slight vibration of the units operating with the

$376440 \mathrm{~m}$ head. It should also be noted that all assessment indices influence the safety of each

377 unit although their contributions may vary significantly in different working heads.

378 Fig. 10 presents the estimated safety degree of the four HGUs under different 379 working heads. The probabilistic results indicate that the most stable HGU is unit 4 with 380 the average safety degree of 0.6282 . Unit 1 is the second most stable unit with the 
average safety degree of 0.6057 . Unit 2 is the third safest unit of the four with the average safety degree of 0.5974 while unit 3 has the highest operational risk with its average safety degree of 0.5793 . Based on the results, the system can safely run in the orders suggested in Fig. 10 when the allowable head fluctuates around 431m, 434m, 437m and $440 \mathrm{~m}$. However, when the hydropower station is not able to predict the working head of HGUs in advance, it is suggested that the optimal operational schedule is as follows: unit 4, unit 1 , unit 2 and unit 3. This provides the safe operating strategy of HGUs to cope with peaks and troughs of electricity demand within the station.

It is also observed, in Fig. 10 that the safety degree of four units for the allowable head of $437 \mathrm{~m}$ is lower than other working heads, changing between the range of $[0.4305$, 0.5004]. That is, the average safety of HUGs is less than 50 percent under the allowable head of $437 \mathrm{~m}$. It can therefore be a reasonable suggestion that the HGUs at the studied station could avoid, if possible, operating with this condition to enhance the operational safety.

\section{Conclusions}

In this paper, a new framework is presented for the safety assessment of HGUs in hydropower stations and addresses the limitations in this research field. The study is carried out based on four on-load HGUs operating at an existing hydropower station in China. A dynamic balance experiment of the units with different allowable heads is conducted to qualitatively investigate the system stability and to obtain the requirements 
402 for further quantitative analyses. This was performed by using the grey correlation 403 analysis and entropy weights method. It is demonstrated that there is a significant 404 difference in the sensitivity and risk contribution of the adopted indices between the 405 allowable heads of $431 \mathrm{~m}, 434 \mathrm{~m}, 437 \mathrm{~m}$ and $440 \mathrm{~m}$. The measurements of the weights 406 reveal that, the safety of units operating with a head of $431 \mathrm{~m}, 434 \mathrm{~m}, 437 \mathrm{~m}$ depend on the 407 combined contribution of mechanical issues and hydraulic imbalance, while the undesired 408 events occurring for units with $440 \mathrm{~m}$ of head may only be caused by mechanical issues.

409 From the grey-entropy assessment results, it can be concluded that the units have their 410 specific safety degree as the allowable head changes. Moreover, a safe operational 411 schedule can follow the order of: unit 4, unit 1, unit 2 and unit 3 . It is anticipated that the 412 proposed method can be adopted for improving the safety of hydropower facilities by 413 providing optimal operational schedules.

\section{Appendix}

\section{Numerical process of the safety degree in HGUs}

417 The aim of the numerical analysis is to establish the grey-entropy correlation degree 418 (see Eq. (7)) to conduct a dynamic safety assessment of on-load HGUs. Eq. (7) is combined 419 with the entropy weights (see Eq. (3)) and the grey correlation coefficients (see Eq. (4)). 420 That is, the numerical analysis consists of three steps to obtain the dynamic safety degree of 421 HGUs: i) based on the measurement data of seventeen indices in Table 4, we calculate the 
422 entropy weight matrix of index $\boldsymbol{W}_{\boldsymbol{i}}$ with respect to different working heads, ii) estimating

423 the correlation coefficient matrix of indices $\xi_{i}(j)$ for different working heads based on the

424 grey correlation equations (see Eqs. (4) to (6)) and iii) substituting the entropy weight

425 matrix $W_{i}$ and correlation coefficient matrix $\xi_{i}(j)$ into the grey-entropy correlation

426 degree (see Eq. (7)). Finally, the dynamic safety degree matrix of studied HGUs $\boldsymbol{\alpha}_{i}$ under

427 different working heads is obtained. A detailed calculation progress is performed as

428 follows.

429 In this study, we have seventeen assessment indices (marked as $j$ ) and four HGUs

430 (marked as $i$ ) operating with four working heads of $431 \mathrm{~m}, 434 \mathrm{~m}, 437 \mathrm{~m}$ and $440 \mathrm{~m}$. The

431 optimum safety matrix is [0], and the assessment matrices of the four HGUs at different

432 working heads, i.e. $\left[\boldsymbol{r}_{i j}\right]_{431 \mathrm{~m}},\left[\boldsymbol{r}_{i j}\right]_{434 \mathrm{~m}},\left[\boldsymbol{r}_{i j}\right]_{437 \mathrm{~m}},\left[\boldsymbol{r}_{\boldsymbol{i j}}\right]_{440 \mathrm{~m}}$, are shown in Table 4 . The

433 normalized method of inverse index expressed in Eq. (1) is used to obtain the standard

434 form of optimum safety matrix and assessment matrices, which are

435

$[\mathbf{0}] \cap\left[\boldsymbol{r}_{i j}\right]_{431 \mathrm{~m}}=$

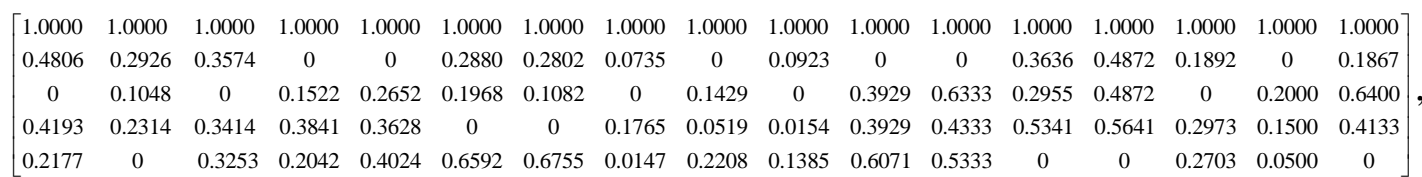

437

$[\mathbf{0}] \cap\left[\boldsymbol{r}_{i j}\right]_{434 \mathrm{~m}}=$

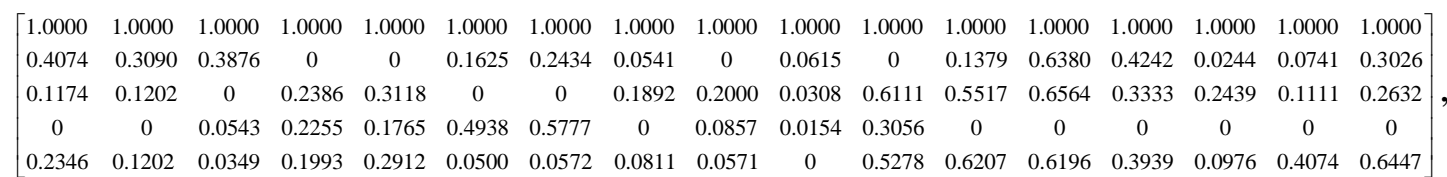




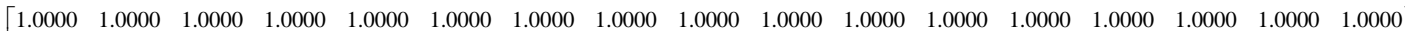
$\begin{array}{llllllllllllllllll}0.2683 & 0.3431 & 0.3411 & 0 & 0 & 0.3426 & 0.2781 & 0.0380 & 0.1321 & 0.3796 & 0.7423 & 0.6098 & 0.7020 & 0.5472 & 0.2336 & 0.2222 & 0.6993\end{array}$

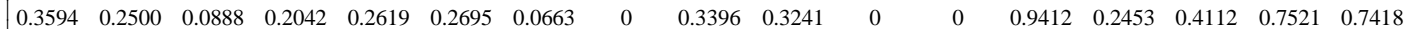
$\begin{array}{lllllllllllllllll}0 & 0.3284 & 0.2944 & 0.3668 & 0.4802 & 0 & 0 & 0.2152 & 0.3679 & 0.3148 & 0.1546 & 0.3293 & 0 & 0.1509 & 0 & 0 & 0\end{array}$

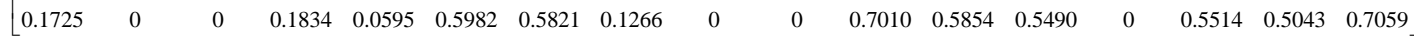

441 and

442

$[\mathbf{0}] \cap\left[\boldsymbol{r}_{i j}\right]_{440 \mathrm{~m}}=$

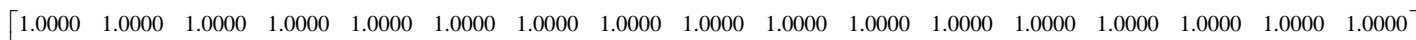

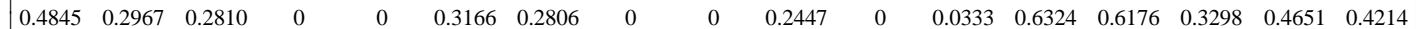

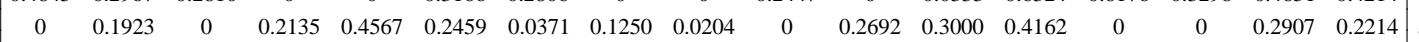

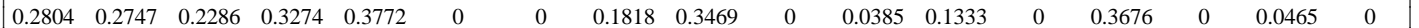

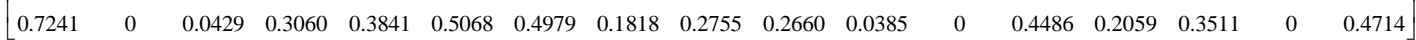

To clearly clarify the proposed method, an example for the assessment process of on-load HGUs at 440m working head is demonstrated as follows:

(i) Entropy weight matrix $\boldsymbol{W}_{i}$ : Based on Eq. (2) and (3), the entropy weight matrix of seventeen indices derived from assessment matrix $\left[\boldsymbol{r}_{i j}\right]_{440 \mathrm{~m}}$ is written as:

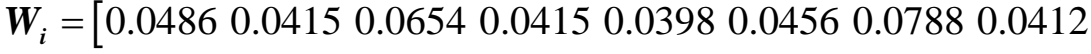

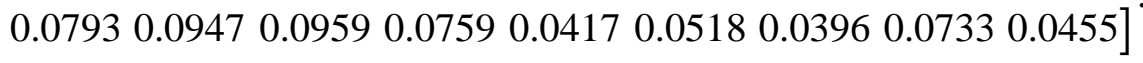

The minimum and maximum differences in the first level in Eq. (5) are obtained as:

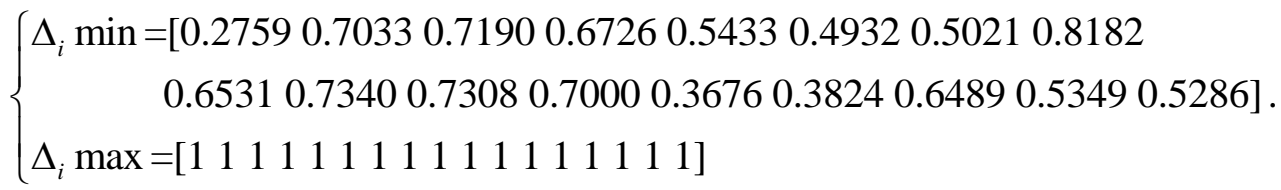

The minimum and maximum differences in the second level in Eq. (6) are obtained

$$
\left\{\begin{array}{l}
\min _{i}\left(\Delta_{i} \min \right)=0.2759 \\
\max _{i}\left(\Delta_{i} \max \right)=1
\end{array} .\right.
$$

We substitute the obtained values for $\Delta_{i} \min , \Delta_{i} \max , \min _{i}\left(\Delta_{i} \min \right)$ and 
457 with respect to the $j$ th factor in the index set $\left[r_{i j}\right]_{440 \mathrm{~m}}$ is estimated as:

$458 \quad \xi_{i}(j)=$

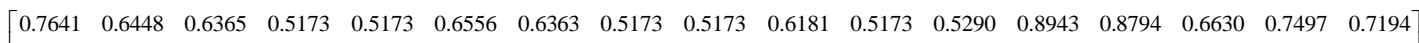
$\begin{array}{lllllllllllllllll}0.5173 & 0.5933 & 0.5173 & 0.6031 & 0.7437 & 0.6187 & 0.5304 & 0.5643 & 0.5244 & 0.5173 & 0.6304 & 0.6466 & 0.7159 & 0.5173 & 0.5173 & 0.6416 & 0.6068\end{array}$ $\begin{array}{llllllllllllllllllllll}0.6362 & 0.6332 & 0.6103 & 0.6617 & 0.6910 & 0.5173 & 0.5173 & 0.5886 & 0.6729 & 0.5173 & 0.5309 & 0.5677 & 0.5173 & 0.6852 & 0.6753 & 0.5338 & 0.5173\end{array}$ • $\left[\begin{array}{lllllllllllllllll}1.0000 & 0.5173 & 0.5325 & 0.6499 & 0.6953 & 0.7812 & 0.7743 & 0.5886 & 0.6337 & 0.6287 & 0.5309 & 0.5173 & 0.7380 & 0.5996 & 0.6454 & 0.5173 & 0.7543\end{array}\right]$

\section{(iii) Grey-entropy correlation degree (also called safety degree) $\alpha_{i_{-} 440 m}$ :}

The grey-entropy correlation degree, $\boldsymbol{\alpha}_{i}$, between the optimum unit and the studied

the working head of $431 \mathrm{~m}$ is

464

$$
\alpha_{i_{-} 440 m}=\left[\begin{array}{c}
0.6350 \\
0.5833 \\
0.5834 \\
0.6399
\end{array}\right], i=1,2,3 \text { and } 4 .
$$

466 head of $431 \mathrm{~m}, 434 \mathrm{~m}$ and $437 \mathrm{~m}$, respectively. The corresponding safety degree matrices

467 of the four HGUs are listed as follows:

$468431 \mathrm{~m}$ working head:

469

$$
\boldsymbol{\alpha}_{i_{-431 m}}=\left[\begin{array}{l}
0.6315 \\
0.6504 \\
0.6738 \\
0.6895
\end{array}\right], i=1,2,3 \text { and } 4 \text {. }
$$

$434 \mathrm{~m}$ working head: 
$472437 \mathrm{~m}$ working head:

$$
\boldsymbol{\alpha}_{i_{-} 437 m}=\left[\begin{array}{c}
0.5004 \\
0.4915 \\
0.4305 \\
0.4974
\end{array}\right], i=1,2,3 \text { and } 4 .
$$

\section{Acknowledgments}

476 This work was supported by the scientific research foundation of National Natural 477 Science Foundation of China--Outstanding Youth Foundation (No. 51622906), National 478 Natural Science Foundation of China (No. 51479173), Fundamental Research Funds for 479 the Central Universities (No. 201304030577), Scientific research funds of Northwest 480 A\&F University (No. 2013BSJJ095), Science Fund for Excellent Young Scholars from 481 Northwest A\&F University and Shaanxi Nova program (No. 2016KJXX-55).

\section{References}

484 [1] Sequeira TN, Santos MS. Renewable energy and politics: A systematic review and 485 new evidence. J Clean Prod 2018; 192: 553-568.

486 [2] Binama M, Su WT, Li XB, Li FC, Shi XZ, An S. Investigation on pump as turbine 487 (PAT) technical aspects for micro hydropower schemes: A state-of-the-art review. Renew $488 \quad$ Sust Energ Rev 2017; 79: 148-179. 
490 impacts associated with hydropower. Renew Sust Energ Rev 2017; 70: 896-904.

491 [4] Holanda PDS, Blanco CJC, Mesquita ALA, Brasil ACP, de Figueiredo NM, Macedo, 492 EN, Secretan Y. Assessment of hydrokinetic energy resources downstream of hydropower 493 plants. Renew Energy 2017; 101: 1203-1214.

494 [5] Yu X, Zhang J, Fan C, Chen S. Stability analysis of governor-turbine-hydraulic 495 system by state space method and graph theory. Energy 2016; 114: 613-22.

496 [6] Chang JX, Li YY, Yuan M, Wang YM. Efficiency evaluation of hydropower station 497 operation: A case study of Longyangxia station in the Yellow River, China. Energy 2017; $498 \quad 135: 23-31$.

499 [7] Li HH, Chen DY, Zhang H, Wu CZ, Wang XY. Hamiltonian analysis of a 500 hydro-energy generation system in the transient of sudden load increasing. Appl Energy $501 \quad 2017 ; 185: 244-253$.

502 [8] Aradag S, Akin H, Celebioglu K. CFD based design of a 4.3MW Francis turbine for 503 improved performance at design and off-design conditions. J Mech Sci Technol 2017; 31: $504 \quad 5041-5049$.

505 [9] Nasselqvist M, Gustavsson R, Aidanpaa JO. Bearing Load Measurement in a 506 Hydropower Unit Using Strain Gauges Installed Inside Pivot Pin. Exp Mech 2012; 52: $507 \quad 361-369$.

508 [10] Majidi M, Etezadi-Amoli M. Recapturing wasted energy in water pressure reducing 509 valves via in-conduit hydropower generators. Measurement 2018; 123: 62-68. 
510 [11] Li CS, Mao YF, Yang JD, Wang ZB, Xu YH. A nonlinear generalized predictive control for pumped storage unit. Renew Energ 2017; 114: 945-959.

[12] Xu BB, Chen DY, Tolo S, Patelli E, Jiang YL. Model validation and stochastic stability of a hydro-turbine governing system under hydraulic excitations. Int J Electr Power Energy Syst 2018; 95: 156-165.

[13] An XL, Pan LP, Zhang F. Analysis of hydropower unit vibration signals based on variational mode decomposition. J Vib Control 2017; 23: 1938-1953.

[14] Li RH, Li CS, Peng XL, Wei W. Electromagnetic vibration simulation of a 250-MW large hydropower generator with rotor eccentricity and rotor deformation. Energies 2017; 10: 2155 .

[15] Kishor N, Singh SP, Raghuvanshi AS. Dynamic simulations of hydro turbine and its state estimation based LQ control. Energy Conv Manag 2006; 47: 3119-3137. [16] $\mathrm{Xu}$
$\mathrm{BB}$, Chen
DY, Gao X, Tomas
C, Patelli
E. Dynamic evolution of a hydraulic-mechanical-electric system with randomly fluctuating speed. Nonlinear Dynam 2018; 92: 1801-1813.

[17] Zhang QF, Karney B, Suo LS, Colombo AF. Stochastic Analysis of Water Hammer and Applications in Reliability-Based Structural Design for Hydro Turbine Penstocks. J Hydraul Eng-ASCE 2011; 137: 1509-1521.

[18] Ferreira AR, Teegavarapu RSV. Optimal and adaptive operation of a hydropower system with unit commitment and water quality constraints. Water Resour Manag 2012; 26: 707-732. 
531 [19] Haguma D, Leconte R, Krau S. Hydropower plant adaptation strategies for climate 532 change impacts on hydrological regime. Can J Civ Eng 2017; 44: 962-970.

533 [20] Feng ZK, Niu WJ, Cheng CT, Wu XY. Optimization of hydropower system 534 operation by uniform dynamic programming for dimensionality reduction. Energy 2017; 535 134: 718-730.

536 [21] Sovacool BK, Walter G. Major hydropower states, sustainable development, and 537 energy security: Insights from a preliminary cross-comparative assessment. Energy 2018; 538 142: 1074-1082.

539 [22] Zou PXW, Lun P, Cipolla D, Mohamed S. Cloud-based safety information and 540 communication system in infrastructure construction. Safety Sci 2017; 98: 50-69.

541 [23] Guo K, Kuai X, Chen YY, Qi L, Zhang L, Liu YF. Risk assessment of land ecology 542 on a regional scale: Application of the relative risk model to the mining city of Daye, 543 China. Hum Ecol Risk Assess 2017; 23: 550-574.

544 [24] Abbassi R, Khan F, Garaniya V, Chai S, Chin C, Hossain KA. An integrated method 545 for human error probability assessment during the maintenance of offshore facilities. 546 Process Saf Environ Protect 2015; 94: 172-179.

547 [25] Arzaghi E, Abaei MM, Abbassi R, Garaniya V, Chin C, Khan F. Risk-based 548 maintenance planning of subsea pipelines through fatigue crack growth monitoring. Eng 549 Fail Anal 2017; 79: 928-939.

550 [26] Wang ZJ, Wang Q, Ai T. Comparative study on effects of binders and curing ages on 551 properties of cement emulsified asphalt mixture using gray correlation entropy analysis. 
Constr Build Mater 2014; 54: 615-622.

553 [27] Traversaro F, Redelico FO. Confidence intervals and hypothesis testing for the 554 Permutation Entropy with an application to epilepsy. Commun Nonlinear Sci Numer 555 Simul 2018; 57: 388-401.

556 [28] Xu XF, Qiao ZJ, Lei YG. Repetitive transient extraction for machinery fault 557 diagnosis using multiscale fractional order entropy infogram. Mech Syst Signal Proc $558 \quad 2018 ; 103: 312-326$.

559 [29] Sun GD, Guan X, Yi X, Zhou Z. Grey relational analysis between hesitant fuzzy sets 560 with applications to pattern recognition. Expert Syst Appl 2018; 92: 521-532.

561 [30] Cui W, Huang JY, Song HF, Xiao M. Development of two new anti-washout 562 grouting materials using multi-way ANOVA in conjunction with grey relational analysis. 563 Constr Build Mater 2017; 156: 184-198.

564 [31] Shaikh F, Ji Q, Shaikh PH, Mirjat NH, Uqaili MA. Forecasting China's natural gas 565 demand based on optimised nonlinear grey models. Energy 2017; 140: 941-951.

566 [32] Deng ZL, Lin WL, Li N, Han K, Hou YL, Zhang L. The uncertainty entropy of 567 low-rate speech quality evaluation and the analyses of the gray correlation. IEICE 568 Electron Express 2015; 12.

569 [33] Huang SC, Dao, TP. Multi-objective Optimal Design of a 2-DOF Flexure-Based 570 Mechanism Using Hybrid Approach of Grey-Taguchi Coupled Response Surface 571 Methodology and Entropy Measurement. Arab J Sci Eng 2016; 41: 5215-5231.

572 [34] Cai KF, Wang DF. Optimizing the design of automotive S-rail using grey relational 
573 analysis coupled with grey entropy measurement to improve crashworthiness. Struct 574 Multidiscip Optim 2017; 56: 1539-1553.

575 [35] You ML, Shu CM, Chen WT, Shyu ML. Analysis of cardinal grey relational grade 576 and grey entropy on achievement of air pollution reduction by evaluating air quality trend 577 in Japan. J Clean Prod 2017; 142: 3883-3889.

578 [36] Song W, Zhu JJ, Zhang ST, Chen Y. Decision Making Method for Dual Uncertain 579 Information based on Grey Incidence Analysis and Grey Relative Entropy Optimization. $580 \quad$ J Grey Syst 2017; 29: 78-98.

581 [37] Xu BB, Chen DY, Zhang H, Zhou R. Dynamic analysis and modeling of a novel 582 fractional-order hydro-turbine-generator unit. Nonlinear Dynam 2015; 81: 1263-1274.

583 [38] Trivedi C, Agnalt E, Dahlhaug OG. Investigations of unsteady pressure loading in a 584 Francis turbine during variable-speed operation. Renew Energ 2017; 113: 397-410.

585 [39] Huang SZ, Ming B, Huang Q, Leng GY, Hou BB. A Case Study on a Combination 586 NDVI Forecasting Model Based on the Entropy Weight Method. Water Resour Manag $587 \quad 2017 ; 31: 3667-3681$.

588 [40] Yuan ZC, Wu LJ, Yuan ZK, Li HW. Shape optimization of welded plate heat 589 exchangers based on grey correlation theory. Appl Therm Eng 2017; 123: 761-769.

590 [41] Feng YX, Hong ZX, Cheng J, Jia LK, Tan JR. Low Carbon-Oriented Optimal 591 Reliability Design with Interval Product Failure Analysis and Grey Correlation Analysis. 592 Sustainability $2017 ; 9$.

593 [42] Wang WP, Yang ZM, Lu Y, Sin YL, Zhang B. The Optimization Degree of Provincial 
594 Industrial Ecosystem and EKC of China-Based on the Grey Correlation Analysis. J Grey 595 Syst 2016; 28: 1-12.

596 [43] National standard of China (GB/T17189-2007). Code for field measurement of 597 vibrations and pulsation in hydraulic machines (turbines, storage pumps and 598 pump-turbines). China National Standardization Management Committee 2007.

599 [44] National standard of China (GB/T 15468-2006). Fundamental technical 600 requirements for hydraulic turbines. China National Standardization Management 601 Committee 2006.

602 


\title{
Safety assessment of hydro-generating units using experiments and grey-entropy correlation analysis
}

\author{
Huanhuan $\mathrm{Li}^{1,2}$, Diyi Chen ${ }^{1,2^{*}}$, Ehsan Arzaghi ${ }^{3}$, Rouzbeh Abbassi ${ }^{4}$, Beibei Xu ${ }^{1,2}$, Edoardo \\ Patelli ${ }^{5}$, Silvia Tolo ${ }^{5}$ \\ ${ }^{1}$ Key Laboratory of Agricultural Soil and Water Engineering in Arid and Semiarid Areas, \\ Ministry of Education, Northwest A\&F University, Shaanxi Yangling 712100, P. R. China \\ ${ }^{2}$ Institute of Water Resources and Hydropower Research, Northwest A\&F University, \\ Shaanxi Yangling 712100, P. R. China \\ ${ }^{3}$ Wind Energy Research Group, Delft University of Technology, Delft 2629HS, \\ Netherlands \\ ${ }^{4}$ School of Engineering, Faculty of Science and Engineering, Macquarie University, \\ Sydney, NSW, Australia \\ ${ }^{5}$ Institute for Risk and Uncertainty, University of Liverpool, Peach Street, Chadwick \\ Building, Liverpool L69 7ZF, United Kingdom
}

\section{Corresponding author: Diyi Chen}

Telephone: 086-181-6198-0277

E-mail: diyichen@nwsuaf.edu.cn

Abstract: This paper focuses on the safety analysis of a nonlinear hydro-generating unit

(HGU) running under different loads. For this purpose, a dynamic balance experiment implemented on an existing hydropower station in China is considered, to qualitatively investigate the stability of the system and to obtain the necessary indices for safety assessment. The experimental data are collected from four on-load units operating at different working heads including 431m, 434m, 437m, and 440m. A quantitative analysis on the safety performance of the four units was carried out by employing an integration of entropy weights method with grey correlation analysis. This assisted in obtaining the safety degree of each unit, providing the risk prompt to the operation of nonlinear 
hydro-generating units. The results confirm that unit 4 has the highest level of safety while unit 3 operates with the lowest safety condition. This provides the optimal operational schedule of HGUs to cope with the fluctuations of electricity demand in the studied station. The proposed methodology in this paper is not only applicable to the HGUs in the studied station but could also be adopted to assess the safety degree of any hydropower facility.

Keywords: hydro-generating unit; dynamic balance experiment; safety analysis; grey-entropy correlation;

\section{Introduction}

Renewable energy is unarguably one of the most critical governing factors for today's increasing global economic and social development [1]. The pressing challenge lies in the sustainable harnessing of reliable, secure and affordable energy [2]. To date, hydropower has been the main renewable source of electrical energy for many countries' power consumption (e.g. 99\% in Norway, $86 \%$ in Brazil and $76 \%$ in Switzerland) due to the environmental consequences of fossil fuels exploitation [3]. The electricity provided by hydropower contributes about $16 \%$ of the world total electricity generation and is expected to grow to $2 \mathrm{GW}$ in thirty years [4]. It is therefore no exaggeration that hydropower represents more than $92 \%$ of generated green energy making it a significant contributor to the global electricity supply [5].

Hydropower stations are the major electricity generation facilities in which the hydro-generating unit (HGU) is the heart of the energy production, transmission and 
conversion in each station [6]. HGU is a complex nonlinear system that integrates the characteristics of fluid, machinery, and electromagnetic induction [7]. A universal HGU is comprised of various coupled components such as hydraulic turbines, shafting systems, generators, governors, and excitation systems ([8] to [12]).

Due to the nonlinear coupled characteristics, several hazardous factors are present within the operation of an HGU including shafting vibrations, electromechanical delays, stochastic instability, and inefficient operation. A large number of literatures have extensively studied such topics from the perspective of individual subcomponents, which supports the research foundation for the safety study in this paper. For instance, literatures ([13], [14]) analyzed the cause of shafting vibrations in an HGU. Literature [15] studied a class of hydro-turbine with electromechanical delays. Researchers in ([16], [17]) modelled stochastic variables of an HGU to analyze its effect on the stability of subcomponents. Researchers in ([18], [19]) studied the adaptation strategy of hydropower systems to improve the operating efficiency. This range of conducted research highlights that the hydropower industry is greatly concerned about the safety of HGU operations and improvements are needed [20]. In particular, with the construction of large-capacity hydropower stations to be completed in the following decades, resolving the stability problems of operation, from the perspective of systemic properties, will be one of the major areas that attracts a great deal of attention from the industry [21]. Although a large number of advanced safety assessment methods have been developed in various research fields such as information science [22], ecological engineering [23] and marine engineering [24, 
$7125]$, the operational safety of HGUs has been rarely investigated and very little evidence of

72 achievements has been previously provided.

To date, the safety analyses of HGUs have mainly focused on investigating the

74 stability of HGU components. The developed methods determine the instability status of

75 the HGU components in terms of narrow hydraulic, mechanical, or electrical angle.

76 However, the integrated safety level of the entire HGU system has not been evaluated from

77 these independent components. Hence, there is a need for a framework that can assess the

78 safety of HGU from the system perspective. Previous researches ([26] to [30]) developed a

79 framework, combining the method of entropy weights and grey correlation theory to

80 investigate the quality problems in different applications such as wastewater treatment, soil

81 detection, and machinery fault. Several studies ([31], [32], and [33]) indicate that the

82 method of entropy weights has a great potential for the assessment of complex systems by

83 measuring the uncertainties of structure indices. The outcome of researches ([34], [35], and

84 [36]) reveal that the grey correlation theory can be adopted for various prediction

85 applications of such complex systems based on incomplete information.

The present paper herein investigates the operational stability of a nonlinear HGU

87 and proposes a methodology for safety assessment of these systems. For this purpose, a

88 dynamic balance experiment is conducted on four HGU units, each with a different

89 working head, in an existing hydropower station in China. The experiment is based on

90 vibration parameter, which is the main risk factor of on-load HGUs. Seventeen indices

91 are extracted to qualitatively assess the operational stability of the units. An effective 

approach integrating the entropy theory and grey correlation is then utilized to quantitatively analyze the safety performance of the studied HGU. This assisted in determining the safety degree of the analyzed four units that run with load, as well as an optimal operational schedule of HGUs coping with peaks and troughs of electricity demand in the studied hydropower station.

The present paper has extensively reviewed the existing literature that are based on the individual subcomponents (e.g. hydro-turbines, shafts and generators) of HGU systems.

The major contribution of the paper, however, is to consider the coupled characteristics of hydraulic, mechanical and electrical subcomponents for investigating the safety of HGU operation. Moreover, there are few researches that have successfully applied dynamic safety assessment to nonlinear HGUs. This paper presents a novel methodology that is significantly more flexible and efficient in dynamic safety assessment of HGUs with an attempt to overcome the limitations of static approaches. The safety degree of HGUs is quantified by using a probabilistic approach, which serves as a tool for monitoring and predicting the risk of accidents in hydropower stations resulting from failure in HGUs. This not only improves the safety of HGU operation, but also effectively reduces the operational and maintenance costs of energy production. The results obtained from this research benefit the operators and risk managers of the hydropower industry serving as a tool for development of risk mitigation strategies. For instance, it enables them to respond to the important question of "how to efficiently and safely arrange the operation of multiple HGUs with respect to different allowing heads". 
114 universal nonlinear HGU is presented. In Section 3 the fundamentals of utilized methods

115 and an overview of the global methodology for safety assessment of HGU are provided.

116 Section 4 discusses the details of the conducted dynamic balance experiment on the

117 studied station's HGU. Section 5 demonstrates the process of safety assessment

118 methodology and presents its highlighted results. Lastly, the key findings of this study are

119 discussed in the conclusion section.

\section{2. A Brief Review of an on-load HGU}

HGU is the key equipment of hydropower stations used to produce, transmit and

123 converse electrical energy, which mainly consists of hydraulic turbines, generators,

124 control systems/governors, excitation systems and inlet and draft pipes [37]. The

125 operation of an HGU is always integrated with a number of other hydraulic components

126 such as surge tank, piping system, water gate and reservoir [38]. The structure of an HGU

127 and the key elements of the hydraulic system are shown in Fig. 1. 


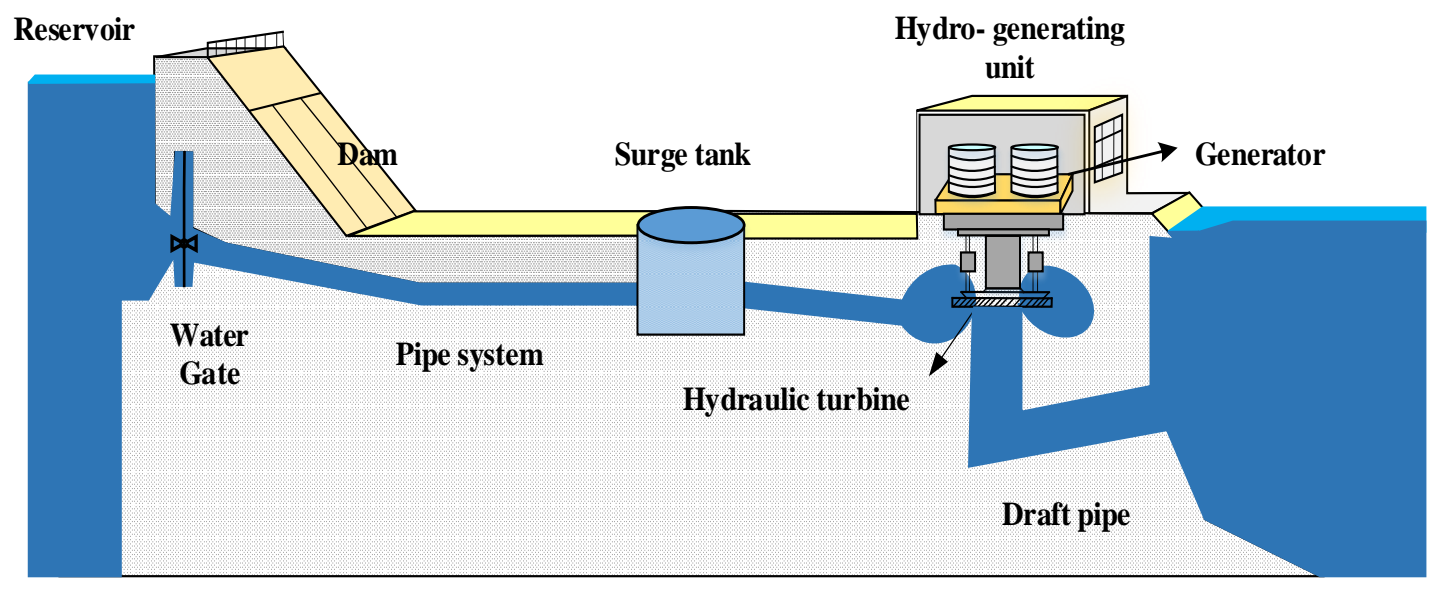

Fig. 1 Schematic of an HGU.

HGU, in fact, is a nonlinear system with multi-attribute characteristics including hydraulic, mechanical, electrical and electromagnetic. An on-load HGU is a system synchronized with the power grid, and its load generally cannot be constantly maintained due to the stochastic load. The on-load HGU may be considered as a dynamic system varying with the changes (decrease or increase) in load. An HGU mainly utilizes pressure and momentum energy to produce power. The working mechanism of an on-load HGU is described as the flow velocity influenced by the effect of blade changes as the system load fluctuates, which in turn generates a reactive force in the flow channel. This drives the hydraulic turbines which generate mechanical energy, and the generator further converts the mechanical energy to electrical energy. The details of an HGU working mechanism is presented in Fig. 2. 

experimental investigations.

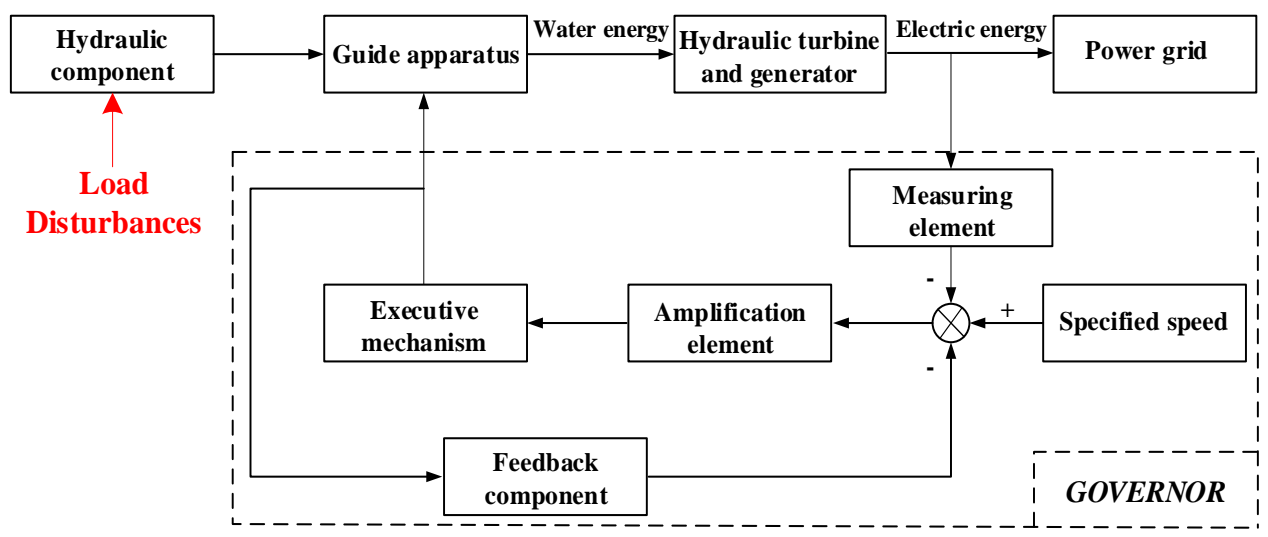

Fig. 2 Details of an on-load HGU working mechanism.

In actual hydropower stations, the dynamic performance of HGUs is hard to detect due to the rapid changes in the operational conditions influenced by internal couplings as well as the external environment. Uncontrolled and abrupt changes in the dynamic variables influencing the operational conditions of the system could result in critical damage to the asset as well as other consequences. It is therefore essential to conduct quantitative assessment of the safety and stability of an HGU, probably based on

\section{Methodology}

Previous researches in this field have focused on developing static safety assessment

153 frameworks for operating HGUs. However, due to the nonlinearity of these systems, 154 attending to the dynamic effects in the analysis are essential for achieving better results. To 155 overcome this shortcoming, an effective method must be developed applicable to 156 hydropower facilities. Through conducting an interdisciplinary research [26, 27], this 

safety assessment of an HGU, a specific index weight is the critical indicator to measure 177 the importance of the selected index, assessing its safety contribution to the studied

section presents the details of an enhanced grey-entropy correlation methodology for dynamic safety analysis of on-load HGUs. The proposed framework is able to improve the imprecision of subjective entropy weights as well as the static evaluation of grey correlation degrees. A major contribution of the established method is in adopting the probabilistic approaches to predict and reflect the real-time safety level of on-load HGUs, which is greatly beneficial when dealing in a timely manner with unexpected accidents and the development of improved safety and risk mitigation strategies.

\subsection{Entropy Weights Method}

The concept of entropy that is derived from thermodynamics theories represents a measure of disorder in a system. Entropy theory was proposed by Shannon, in 1948, to reflect the uncertainty in information science, it has been applied in various research fields for its precision and flexibility [39].

Two approaches can be applied for determining the weights of indices, known as subjective fixed weight and objective fixed weight methods. Entropy weight method, as an objective approach, is based on the amount of data, overcoming the subjectivity issues as it is independent of expert judgment. The main idea of entropy method is to determine the weights by index variations. In general, a smaller index weight represents a larger degree of index variation, meaning that the index may provide more assessment information and have significant influence on the stability of the system. In the entropy 
system.

179 Assuming that there are $m$ assessment indices and $n$ assessment units, the assessment 180 data is transformed into a form of standardization that employs a normalized method of 181 inverse index, shown in Eq. (1) [40].

$$
r_{i j}=\frac{\max x_{i j}-x_{i j}}{\max x_{i j}-\min x_{i j}}, i=1,2, \ldots, m \text { and } j=1,2, \ldots, n,
$$

where $\left\{\boldsymbol{r}_{i j}\right\}_{\boldsymbol{m} \times \boldsymbol{n}}$ is the normalized set of inverse index. $\max x_{i j}$ and $\min x_{i j}$ are the maximum and minimum values in the index column of assessment units, respectively. It should be noted that the lower value of inverse index is most important in ensuring safe operation of an HGU.

$$
E_{i}=-\frac{\sum_{j=1}^{n} r_{i j} \ln r_{i j}}{\ln n}, i=1,2, \ldots, m
$$

and the index weight of $i$ is obtained as:

$$
\omega_{i}=\frac{1-E_{i}}{\sum_{i=1}^{m}\left(1-E_{i}\right)}, \quad \sum_{j=1}^{n} \omega_{i}=1, \quad \omega_{i} \in[0,1]
$$

191 Therefore, the index weight set $\boldsymbol{W}_{i}$ is $\left[\omega_{1}, \omega_{2}, \ldots, \omega_{n}\right]$.

\subsection{Grey-entropy Correlation Method}

Grey system is used to describe an uncertain system that has the characteristic of

194 partial information loss, and grey correlation theory is a powerful tool to query the quality of a system with poor information [41]. An on-load HGU is an engineering system 
incorporating a degree of uncertainty and therefore it can be assessed by the grey

197 correlation theory. The concept of using grey theory is to find the possible motion rule

198 from the disordered and fuzzy data. Specifically, it is the similarity of an index in

199 different assessment units that is the key factor for measuring the variation between the

200 indices. A greater similarity between indices means that the grey correlation of a studied

201 unit is more optimal. There are no requirements for the size and characteristics of data in

202 a grey correlation analysis which overcomes the shortcomings of traditional regression

203 analyses.

204 Based on the normalized set of inverse index $\left\{\boldsymbol{r}_{i j}\right\}_{m \times n}$ mentioned in Eq. (1), the

205 index column is expressed as $\boldsymbol{x}_{1}, \boldsymbol{x}_{2}, \ldots, \boldsymbol{x}_{\boldsymbol{m}}$. It should be noted that, there are $i$ assessment

206 plans in the analysis, i.e., $\boldsymbol{x}_{i}=\left[x_{i}(1), x_{i}(2), \ldots, x_{i}(n)\right]$, where $\boldsymbol{x}_{0}$ is assumed to be the

207 optimum plan. Therefore, the correlation coefficient, $\boldsymbol{\xi}_{i}(j)$, between $\boldsymbol{x}_{0}$ and $\boldsymbol{x}_{i}$ with

208 respect to the $j^{\text {th }}$ factor in the index set $\left\{\boldsymbol{r}_{i j}\right\}_{m \times n}$ is expressed as [42]:

$$
\boldsymbol{\xi}_{i}(j)=\frac{\min _{i}\left(\Delta_{i} \min \right)+\rho \max _{i}\left(\Delta_{i} \max \right)}{\Delta_{i}+\rho \max _{i}\left(\Delta_{i} \max \right)}, i=1,2, \ldots, m \text { and } j=1,2, \ldots, n,
$$

210 where $\Delta_{i}$ is equal to $\left|x_{0}(j)-x_{i}(j)\right|, \rho$ is the resolution coefficient that changes

211 within the interval $[0,1]$, but generally it is set at $0.5 . \Delta_{i} \min$ and $\Delta_{i}$ max denote the

212 minimum and maximum differences in the first level respectively, while $\min _{i}\left(\Delta_{i} \min \right)$

213 and $\max _{i}\left(\Delta_{i} \max \right)$ are the minimum and maximum differences in the second level,

214 respectively. The expressions for each of these terms are shown as follows: 


$$
\left\{\begin{array}{l}
\Delta_{i} \min =\min _{j}\left|x_{0}(j)-x_{i}(j)\right| \\
\Delta_{i} \max =\max _{j}\left|x_{0}(j)-x_{i}(j)\right|
\end{array}\right.
$$

216 and

$$
\left\{\begin{array}{l}
\min _{i}\left(\Delta_{i} \min \right)=\min _{i} \min _{j}\left|x_{0}(j)-x_{i}(j)\right| \\
\max _{i}\left(\Delta_{i} \max \right)=\max _{i} \max _{j}\left|x_{0}(j)-x_{i}(j)\right|
\end{array},\right.
$$

219 the correlation coefficient $\xi_{i}(j)$ for the $i^{\text {th }}$ studied unit to obtain its integrating safety

220 degree. Therefore, the grey correlation degree, $\boldsymbol{\alpha}_{i}$, between the optimum unit and the 221 studied unit $i$ is given by the grey-entropy correlation equation as follows:

$$
\boldsymbol{\alpha}_{i}=\sum_{j=1}^{m} \boldsymbol{W}_{i} \boldsymbol{\xi}_{i}(j), \quad \mathbf{0} \leq \boldsymbol{\alpha}_{i} \leq \mathbf{1}
$$

In Eq. (7), the obtained grey correlation degree $\boldsymbol{\alpha}_{i}$, also defined as the safety degree,

224 assists in assessing the safety level of a multi-unit HGU from a probabilistic point of view.

225 That is, a higher value of $\boldsymbol{\alpha}_{i}$ corresponds to a safer HGU thus for instance, a system

226 with $\boldsymbol{\alpha}_{i}=\mathbf{1}$ has the maximum level of reliability.

\section{$227 \quad 3.3$ Global Methodology}

This paper presents a novel framework for the dynamic safety assessment of HGUs

229 by combining the entropy weight method with the grey correlation analysis. The major 230 novel components of the proposed method consist of:- firstly, the method overcomes the

231 subjectivity of traditional methods in determining the weight coefficients of assessment 232 indices, which improves the accuracy of the results and provides a more scientific 
representation. Secondly, the method completely transforms the static safety assessment into a dynamic practice by substituting the dynamic entropy weights (i.e. Eq. (3)) into the relationship for obtaining the grey correlation degree (i.e. Eq. (7)). Thirdly, few existing studies have been proven to be successful in conducting a probabilistic safety analysis of 237 nonlinear HGUs.

The steps of the developed methodology in this paper are provided in Fig. 3, and summarized as follows.

(1) A dynamic balance experiment is carried out on the existing HGUs for different allowing heads, to qualitatively analyze the dynamic operational behavior of a hydropower station. The obtained data, $m$ assessment indices for $n$ studied HGUs, is later used to 243 conduct a quantitative safety analysis.

(2) Dynamic entropy weights (see Eq. (3)) are developed to estimate the contribution

245 of the indices on HGSs' stability with respect to time. For this purpose, the indices with significant influence on HGS' operation under various allowing heads are identified.

(3) The grey-entropy correlation degrees (see Eq. (7)), combined with the dynamic 248 entropy weights (see Eq. (3)) and grey correlation coefficients (see Eq. (4)), are used to 249 evaluate the safety degree of $n$ studied HGUs. The safety degree is expressed by 250 probability values.

(4) Based on the quantitative analysis, the time-varying safety state of HGUs and any accidents are revealed. This enables the technicians and operators of hydropower stations 253 to make an optimal operational schedule of HGUs for dealing with fluctuations of 
254 electricity generation and demand.

255 A detailed illustration of the numerical process of entropy weights and safety

256 degrees is presented in the Appendix.

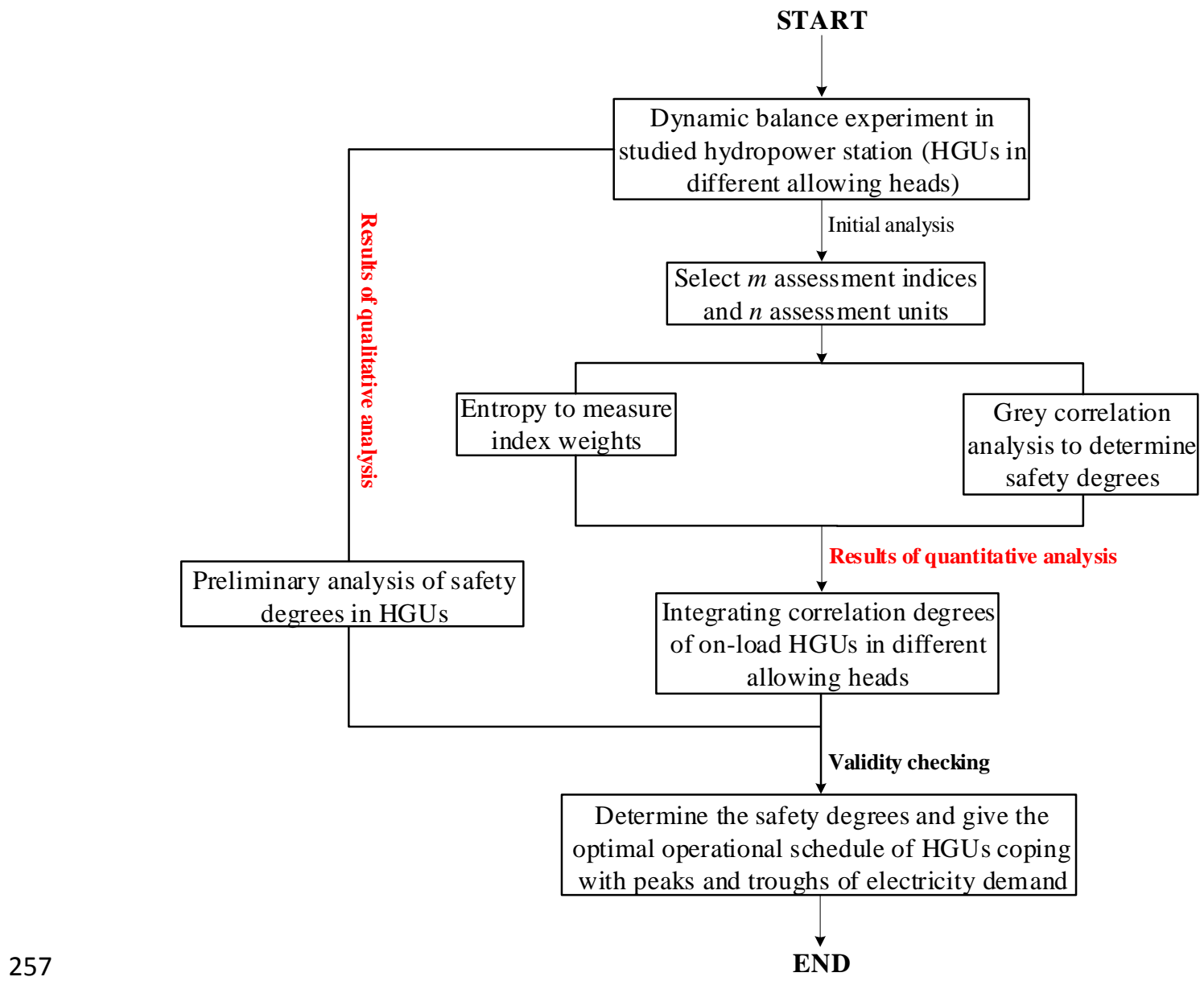

Fig. 3 Proposed framework for safety assessment of on-load HGUs.

260 4. Dynamic Balance Experiment on HGUs

261 In order to conduct a safety analysis on the HGU with load, a dynamic balance

262 experiment was carried out on the HGU in an existing hydropower station in China and 263 seventeen critical safety indices (i.e. X1-X17) were determined. These indices could 
264 reflect the instability of the system with respect to vibrations and pressure pulsations in 265 units. There are four Francis HGUs at the studied station, with installed and unit capacity 266 of $1050 \mathrm{MW}$ and $262.5 \mathrm{MW}$, respectively. In this experiment, the utilized sensors and 267 measurement equipment for vibration analysis include: the PSTA-H vibration 268 instrumentation of HGU, the TTS216 dynamic signal instrumentation of HGU, a CWY 269 eddy current displacement sensor, a DP low-frequency vibration sensor, a KYB pressure 270 transmitter and shielded signal cables. Some of the technical details of the four HGUs

271 tested in the experiment are listed in Table 1, and the arrangements of the monitoring 272 points on the HGUs, as well as the type of acquired data at each point, are presented in 273 Fig. 4.

274 Table 1 Information of the Francis hydraulic turbine of four HGUs in an existing 275 hydropower station.

\begin{tabular}{|c|c|c|c|}
\hline \multicolumn{4}{|c|}{ Information of Francis Hydraulic Turbines } \\
\hline Type & HLS270-LJ-680 & Nominal power & $267.85 \mathrm{MW}$ \\
\hline Nominal head & $64 \mathrm{~m}$ & Nominal flow & $460.46 \mathrm{~m}^{3} / \mathrm{s}$ \\
\hline Nominal speed & $93.75 \mathrm{rpm}$ & Runaway speed & $185 \mathrm{rpm}$ \\
\hline $\begin{array}{l}\text { Number of runner } \\
\text { blades }\end{array}$ & 13 & $\begin{array}{l}\text { Number of movable } \\
\text { guide vanes }\end{array}$ & 24 \\
\hline \multicolumn{4}{|c|}{ Information of Generators } \\
\hline Type & SF265-64/15000 & Nominal capacity & 291.7MVA \\
\hline Stator voltage & $15750 \mathrm{~V}$ & Stator current & $10692 \mathrm{~A}$ \\
\hline Power factor & 0.9 & Exciting voltage & $350 \mathrm{~V}$ \\
\hline Exciting current & $1900 \mathrm{~A}$ & Nominal frequency & $50 \mathrm{~Hz}$ \\
\hline \multicolumn{4}{|c|}{ Information of Governors } \\
\hline Type & PFWT-200-6.3 & $\begin{array}{l}\text { Main configuration } \\
\text { diameter }\end{array}$ & $200 \mathrm{~mm}$ \\
\hline Operating oil pressure & $6.3 \mathrm{MPa}$ & Servomotor stroke & $780 \mathrm{~mm}$ \\
\hline $\begin{array}{l}\text { Lower guide bearing } \\
\text { clearance }\end{array}$ & $0.15 \sim 0.2 \mathrm{~mm}$ & $\begin{array}{l}\text { Upper guide bearing } \\
\text { clearance }\end{array}$ & $0.15 \sim 0.2 \mathrm{~mm}$ \\
\hline Water guide bearing & $0.2 \sim 0.25 \mathrm{~mm}$ & Cylinder diameter of & $640 \mathrm{~mm}$ \\
\hline
\end{tabular}




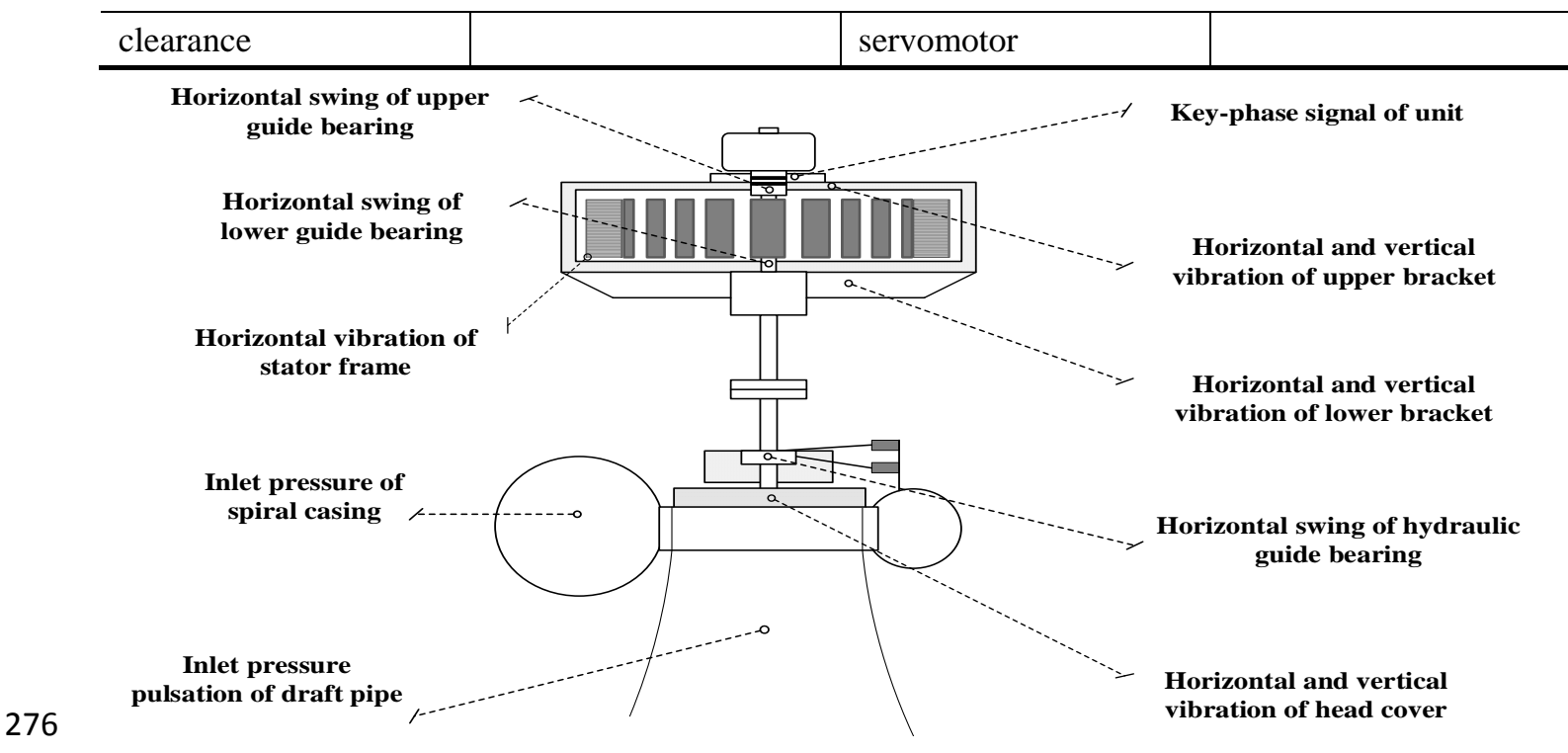

Fig. 4 Arrangements of monitoring points on HGU and type of recorded data at each point in

dynamic balance experiment in an existing hydropower station.

The initial running states of the four HGUs are different due to the internal coupled characteristics and external environment. A start-up test and a turbine-speed test are carried out for different HGUs before the dynamic balance experiments. This results in identifying the initial running state of the four HGUs, including that the rotating and fixed components for HGUs 1 and 4 operate normally and their vibration and swing values meet the design requirements. For HGUs 2 and 3, the start-up test shows that the rotating and fixed components run without abnormal friction or collision. Based on the turbine speed test at nominal speed for HGU 2, it is found that the horizontal vibration of upper 287 bracket $(290 \mu \mathrm{m})$, vertical vibration of upper bracket $(157 \mu \mathrm{m})$, swing of upper guide 288 bearing $(335 \mu \mathrm{m})$, swing of lower guide bearing $(417 \mu \mathrm{m})$ and swing of hydraulic guide bearing $(382 \mu \mathrm{m})$ exceed the design requirements. Similarly for HGU 3, the horizontal 
vibration of upper bracket $(203 \mu \mathrm{m})$ and swing of hydraulic guide bearing $(657 \mu \mathrm{m})$

exceed the design requirements. Moreover, the actual operating conditions for four HGUs Table 2.

Table 2 Actual operating conditions for four HGUs with different allowable heads $(431 \mathrm{~m}$, $434 \mathrm{~m}, 437 \mathrm{~m}$ and $440 \mathrm{~m}$ ) used in the dynamic balance experiment.

\section{HGU 1}

\begin{tabular}{l|c|c|c}
\hline \multicolumn{2}{c}{ Actual upstream head } & Actual downstream head & Actual head of station \\
\hline $431 \mathrm{~m} \mathrm{Head}$ & $431.71 \mathrm{~m}$ & $366.64 \mathrm{~m}$ & $65.07 \mathrm{~m}$ \\
\hline $434 \mathrm{~m} \mathrm{Head}$ & $433.60 \mathrm{~m}$ & $366.36 \mathrm{~m}$ & $67.24 \mathrm{~m}$ \\
\hline $437 \mathrm{~m} \mathrm{Head}$ & $436.40 \mathrm{~m}$ & $366.24 \mathrm{~m}$ & $70.16 \mathrm{~m}$ \\
\hline $440 \mathrm{~m} \mathrm{Head}$ & $439.40 \mathrm{~m}$ & $367.98 \mathrm{~m}$ & $71.42 \mathrm{~m}$ \\
\hline
\end{tabular}

HGU 2

\begin{tabular}{l|c|c|c}
\hline \multicolumn{2}{c}{ Actual upstream head } & Actual downstream head & Actual head of station \\
\hline $431 \mathrm{~m} \mathrm{Head}$ & $431.92 \mathrm{~m}$ & $366.11 \mathrm{~m}$ & $65.81 \mathrm{~m}$ \\
\hline $434 \mathrm{~m}$ head & $433.23 \mathrm{~m}$ & $365.62 \mathrm{~m}$ & $67.61 \mathrm{~m}$ \\
\hline $437 \mathrm{~m} \mathrm{head}$ & $437.33 \mathrm{~m}$ & $367.16 \mathrm{~m}$ & 70.17 \\
\hline $440 \mathrm{~m}$ head & $439.60 \mathrm{~m}$ & $368.29 \mathrm{~m}$ & $71.31 \mathrm{~m}$ \\
\hline \multicolumn{4}{c}{ HGU 3 }
\end{tabular}

\begin{tabular}{l|c|c|c}
\hline \multicolumn{2}{c}{ Actual upstream head } & Actual downstream head & Actual head of station \\
\hline $431 \mathrm{~m}$ head & $431.93 \mathrm{~m}$ & $367.19 \mathrm{~m}$ & $64.74 \mathrm{~m}$ \\
\hline $434 \mathrm{~m}$ head & $433.14 \mathrm{~m}$ & $366.27 \mathrm{~m}$ & $66.87 \mathrm{~m}$ \\
\hline $437 \mathrm{~m}$ head & $437.14 \mathrm{~m}$ & $367.48 \mathrm{~m}$ & $69.66 \mathrm{~m}$ \\
\hline $440 \mathrm{~m}$ head & $439.96 \mathrm{~m}$ & $367.87 \mathrm{~m}$ & $72.09 \mathrm{~m}$ \\
\hline
\end{tabular}

HGU 4

\begin{tabular}{l|c|c|c}
\hline \multicolumn{2}{c}{ Actual upstream head } & Actual downstream head & Actual head of station \\
\hline $431 \mathrm{~m}$ head & $432.66 \mathrm{~m}$ & $367.38 \mathrm{~m}$ & $65.28 \mathrm{~m}$ \\
\hline $434 \mathrm{~m}$ head & $433.31 \mathrm{~m}$ & $365.92 \mathrm{~m}$ & $67.39 \mathrm{~m}$ \\
\hline $437 \mathrm{~m} \mathrm{head}$ & $437.87 \mathrm{~m}$ & $367.97 \mathrm{~m}$ & $69.90 \mathrm{~m}$ \\
\hline $440 \mathrm{~m}$ head & $439.60 \mathrm{~m}$ & $367.67 \mathrm{~m}$ & $71.93 \mathrm{~m}$ \\
\hline
\end{tabular}

297 station varies within the range of $431 \mathrm{~m}$ to $440 \mathrm{~m}$. Four typical allowable heads (i.e. $431 \mathrm{~m}$,

$298434 \mathrm{~m}, 437 \mathrm{~m}$ and 440m) were chosen to conduct the dynamic balance experiment, where 
299 vibration, swing and water pressure were measured. Based on the requirement of the actual 300 operation in this station, the measurements were taken for various on-load conditions 301 within the load range of $120 \mathrm{MW}$ to $265.2 \mathrm{MW}$. The necessary indices in this experiment 302 were selected to qualitatively investigate the stability of four HGUs, and the results are 303 shown in Figs. 5 to 8.

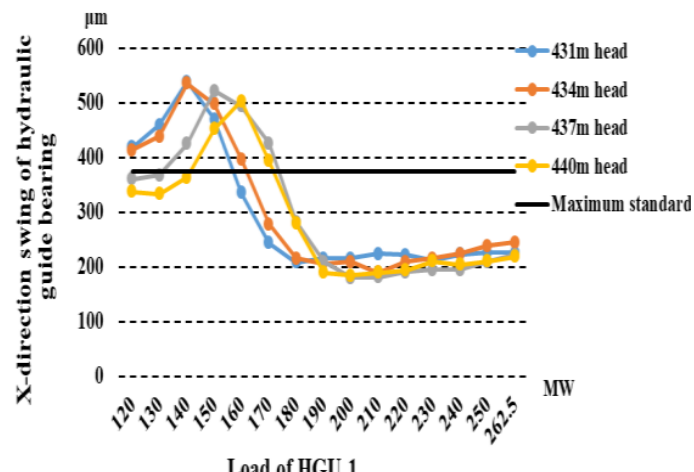

(a)

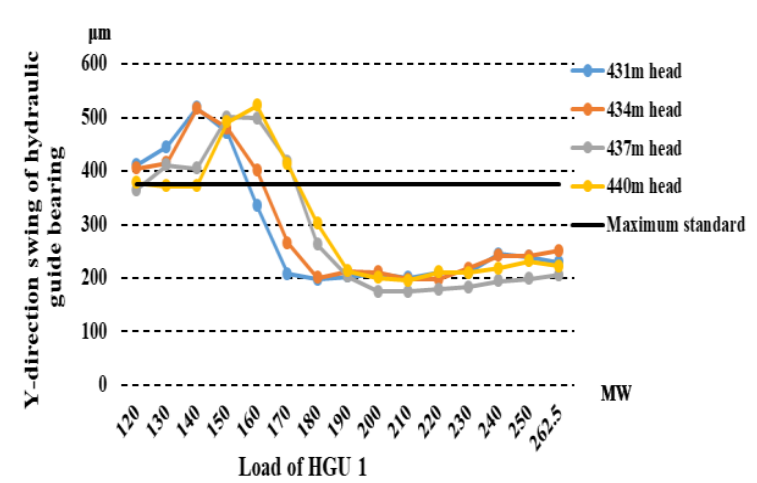

(b)

Fig. 5 Measurements of vibration property in dynamic balance experiment of HGU 1 at an

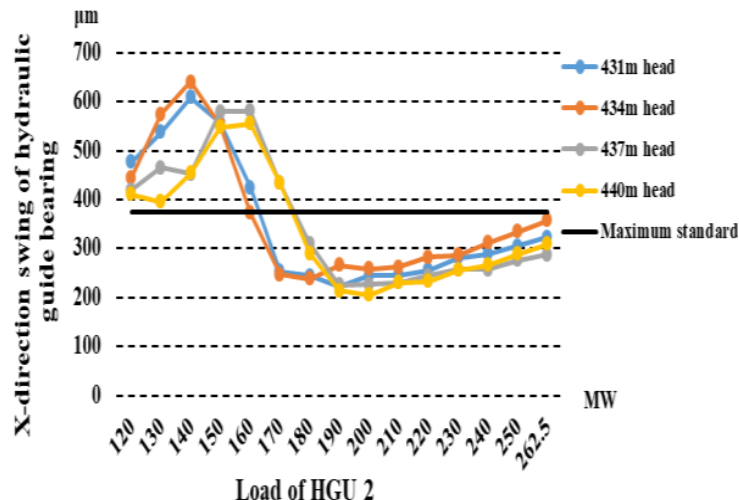

(a)

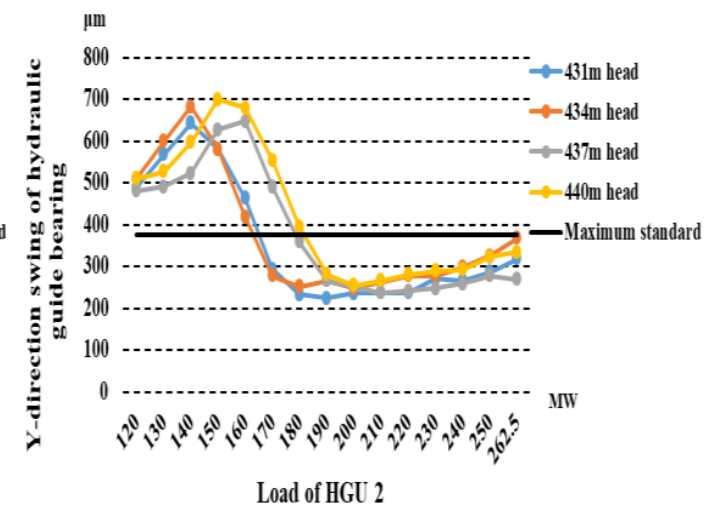

(b) 


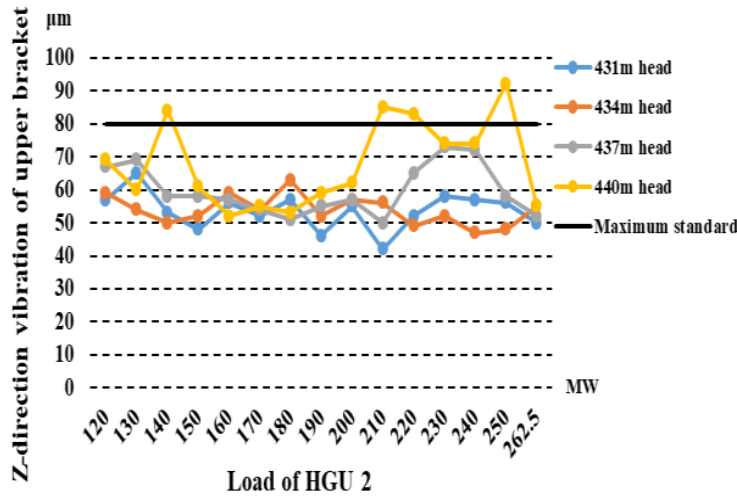

(c)

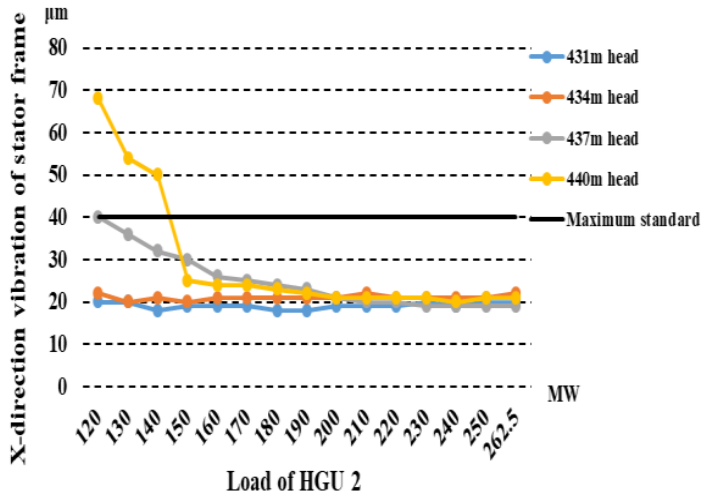

(d)

312 Fig. 6 Measurements of vibration property in dynamic balance experiment of HGU 2 at an existing hydropower station, China.

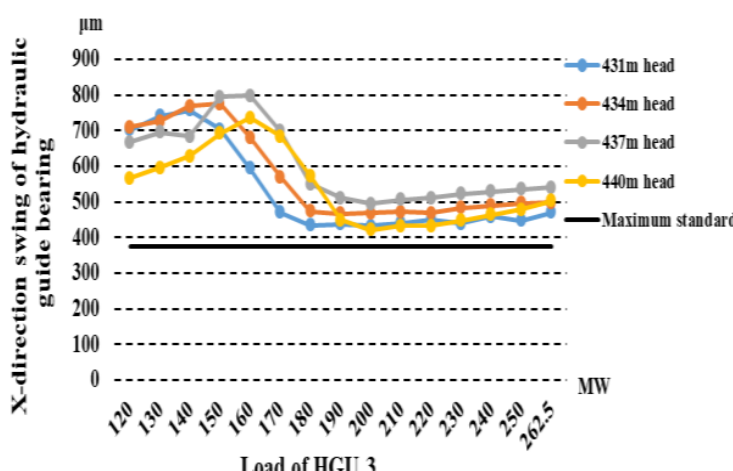

(a)

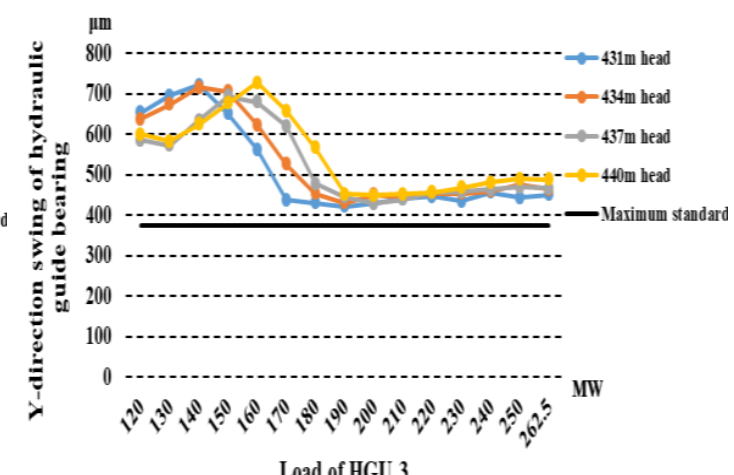

(b)

316 Fig. 7 Measurements of vibration property in dynamic balance experiment of HGU 3 at an existing hydropower station, China.

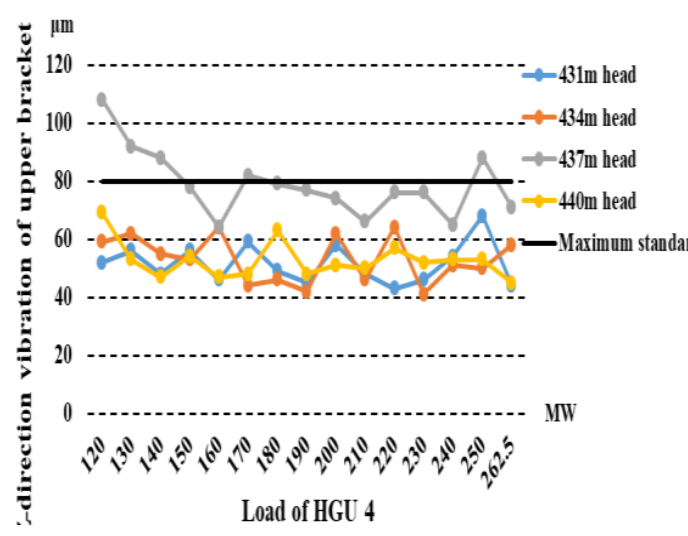

(a)

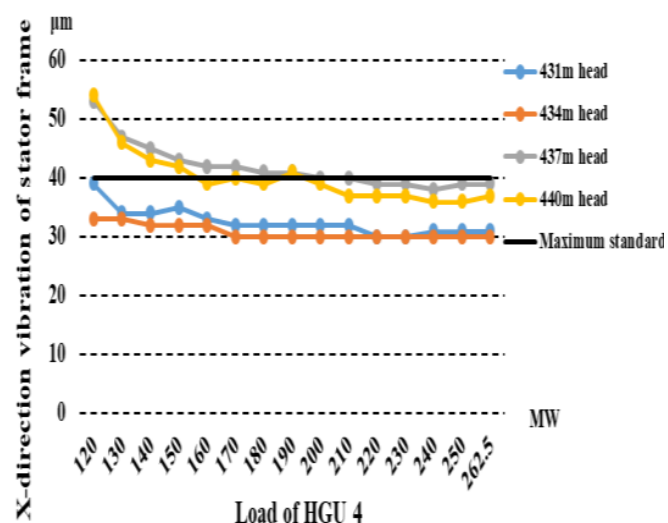

(b)

Fig. 8 Measurements of vibration property in dynamic balance experiment of HGU 4 at an existing hydropower station, China. 
44]. The allowable range for all indices (X1-X17) are listed in Table 3.

Table 3 Allowable ranges of HGU's indices (X1-X17) for safety operation from the national standards $[43,44]$.

\begin{tabular}{|c|c|c|c|}
\hline Index (X1-X9) & $\begin{array}{c}\text { Allowable } \\
\text { range }\end{array}$ & Index (X10-X17) & $\begin{array}{c}\text { Allowable } \\
\text { range }\end{array}$ \\
\hline $\begin{array}{l}\text { Inlet pressure pulsation of draft } \\
\text { pipe (X1) }\end{array}$ & $0 \sim 64 \mathrm{kPa}$ & $\begin{array}{l}\text { Z-direction vertical vibration of } \\
\text { upper bracket (X10) }\end{array}$ & $0 \sim 80 \mu \mathrm{m}$ \\
\hline $\begin{array}{l}\text { X-direction swing of upper } \\
\text { guide bearing }(\mathrm{X} 2)\end{array}$ & $0 \sim 300 \mu \mathrm{m}$ & $\begin{array}{l}\text { X-direction horizontal vibration } \\
\text { of lower bracket (X11) }\end{array}$ & $0 \sim 110 \mu \mathrm{m}$ \\
\hline $\begin{array}{l}\text { Y-direction swing of upper } \\
\text { guide bearing (X3) }\end{array}$ & $0 \sim 300 \mu \mathrm{m}$ & $\begin{array}{l}\text { Y-direction horizontal vibration } \\
\text { of lower bracket (X12) }\end{array}$ & $0 \sim 110 \mu \mathrm{m}$ \\
\hline $\begin{array}{l}\mathrm{X} \text {-direction swing of lower } \\
\text { guide bearing }(\mathrm{X} 4)\end{array}$ & $0 \sim 300 \mu \mathrm{m}$ & $\begin{array}{l}\text { Z-direction vertical vibration of } \\
\text { lower bracket (X13) }\end{array}$ & $0 \sim 80 \mu \mathrm{m}$ \\
\hline $\begin{array}{l}\text { Y-direction swing of lower } \\
\text { guide bearing (X5) }\end{array}$ & $0 \sim 300 \mu \mathrm{m}$ & $\begin{array}{l}\text { X-direction vibration of stator } \\
\text { frame }(\mathrm{X} 14)\end{array}$ & $0 \sim 40 \mu \mathrm{m}$ \\
\hline $\begin{array}{l}\text { X-direction swing of hydraulic } \\
\text { guide bearing (X6) }\end{array}$ & $0 \sim 375 \mu \mathrm{m}$ & $\begin{array}{l}\text { X-direction horizontal vibration } \\
\text { of head cover (X15) }\end{array}$ & $0 \sim 90 \mu \mathrm{m}$ \\
\hline $\begin{array}{l}\text { Y-direction swing of hydraulic } \\
\text { guide bearing }(X 7)\end{array}$ & $0 \sim 375 \mu \mathrm{m}$ & $\begin{array}{l}\text { Y-direction horizontal vibration } \\
\text { of head cover (X16) }\end{array}$ & $0 \sim 90 \mu \mathrm{m}$ \\
\hline $\begin{array}{c}\text { X-direction horizontal } \\
\text { vibration of upper bracket (X8) }\end{array}$ & $0 \sim 110 \mu \mathrm{m}$ & $\begin{array}{l}\text { Z-direction vertical vibration of } \\
\text { head cover (X17) }\end{array}$ & $0 \sim 110 \mu \mathrm{m}$ \\
\hline $\begin{array}{l}\text { Y-direction horizontal vibration } \\
\text { of upper bracket (X9) }\end{array}$ & $0 \sim 110 \mu \mathrm{m}$ & & \\
\hline
\end{tabular}

As illustrated in Table 3 and Figs. 5 to 8, each HGU has a level exceeding the

328 allowable vibrations. Through a comparison of the results, it can be seen that the most

329 stable HGU is unit 4 with the minimum vibration in the upper bracket (along Z-direction)

330 and in its stator frame (along X-direction). It can be seen in Figs. 5 to 7, that the vibration

331 of units 1, 2 and 3 are caused by two indices, i.e. swing of the hydraulic guide bearing

332 along $\mathrm{X}$ and $\mathrm{Y}$ directions. However, it should be noted that the vibration magnitude of 
these units is different where $Y^{3}>Y^{2}>Y^{1}$ and $X^{3}>X^{2}>X^{1}$ (e.g. $Y^{3}$ and $X^{3}$ refer to the magnitude of vibration in unit 3 along $\mathrm{Y}$ and $\mathrm{X}$ directions, respectively). The results of qualitative analysis highlight that the lowest level of safety among the studied units at the studied station is for unit 4 , while unit 2 shows a more stable operation. Unit 1 has a higher safety level than unit 2, however, it does not provide an optimal condition. During the analysis of unit 3 responses, additional vibrations were observed in the upper bracket (along Z-direction) and the stator frame (along X-direction). Since it could not be determined, based on a qualitative assessment, to what extent the different indices affect the operational performance of the four HGUs, a rigorous quantitative analysis is required to investigate the safety condition of these four units.

\section{Analysis of HGUs}

In order to more effectively analyze the safety of the HGUs at the studied station, the grey correlation method is employed based on the results of dynamic balance experiments. For this purpose, maximum vibrations of the seventeen indices are firstly adopted from the experiment results, as listed in Table 4. The maximum vibration of selected index is considered as the assessment criteria in qualitative analysis, where the optimum level of safety is set as $0 \mu \mathrm{m}$ due to the characteristic of inverse indices. Results of the grey correlation analysis for the four units are presented in Figs. 9 and 10.

Table 4 Measured Data: Maximum vibrations of seventeen assessment indices for HGUs (1-4) at an existing hydropower station, China. 


\begin{tabular}{|c|c|c|c|c|c|c|c|c|}
\hline \multicolumn{5}{|c|}{$431 \mathrm{~m} \mathrm{Head}$} & \multicolumn{4}{|c|}{$434 \mathrm{~m} \mathrm{Head}$} \\
\hline Index & HGU 1 & HGU 2 & HGU 3 & HGU 4 & HGU 1 & HGU 2 & HGU 3 & HGU 4 \\
\hline $\mathrm{X} 1$ & 32.69 & 62.94 & 36.55 & 49.24 & 48.73 & 72.58 & 70.05 & 82.23 \\
\hline $\mathrm{X} 2$ & 162 & 205 & 176 & 229 & 161 & 205 & 185 & 233 \\
\hline $\mathrm{X} 3$ & 160 & 249 & 164 & 168 & 158 & 258 & 193 & 244 \\
\hline $\mathrm{X} 4$ & 289 & 245 & 178 & 230 & 306 & 233 & 180 & 237 \\
\hline $\mathrm{X} 5$ & 328 & 241 & 209 & 196 & 340 & 234 & 203 & 280 \\
\hline X6 & 539 & 608 & 757 & 258 & 536 & 640 & 775 & 324 \\
\hline $\mathrm{X} 7$ & 519 & 643 & 721 & 234 & 516 & 682 & 716 & 288 \\
\hline $\mathrm{X} 8$ & 63 & 68 & 56 & 67 & 70 & 60 & 72 & 74 \\
\hline $\mathrm{X} 9$ & 77 & 66 & 73 & 60 & 70 & 56 & 60 & 64 \\
\hline $\mathrm{X} 10$ & 59 & 65 & 64 & 56 & 61 & 63 & 56 & 64 \\
\hline X11 & 28 & 17 & 17 & 11 & 36 & 14 & 18 & 25 \\
\hline $\mathrm{X} 12$ & 30 & 11 & 17 & 14 & 25 & 13 & 21 & 29 \\
\hline $\mathrm{X} 13$ & 56 & 62 & 41 & 88 & 59 & 56 & 58 & 163 \\
\hline X14 & 20 & 20 & 17 & 39 & 19 & 22 & 17 & 33 \\
\hline $\mathrm{X} 15$ & 30 & 37 & 26 & 27 & 40 & 31 & 56 & 41 \\
\hline $\mathrm{X} 16$ & 20 & 16 & 17 & 19 & 25 & 24 & 26 & 27 \\
\hline $\mathrm{X} 17$ & 61 & 27 & 44 & 75 & 53 & 56 & 59 & 76 \\
\hline \multicolumn{9}{|c|}{ Maximum vibrations $(\mu \mathrm{m})$} \\
\hline \multicolumn{5}{|c|}{$437 \mathrm{~m} \mathrm{Head}$} & \multicolumn{4}{|c|}{ 440m Head } \\
\hline Index & HGU 1 & HGU 2 & HGU 3 & HGU 4 & HGU 1 & HGU 2 & HGU 3 & HGU 4 \\
\hline $\mathrm{X} 1$ & 69.89 & 61.19 & 95.52 & 79.04 & 86.67 & 168.14 & 121 & 46.39 \\
\hline $\mathrm{X} 2$ & 134 & 153 & 137 & 204 & 128 & 147 & 132 & 182 \\
\hline $\mathrm{X} 3$ & 141 & 195 & 151 & 214 & 151 & 210 & 162 & 201 \\
\hline $\mathrm{X} 4$ & 289 & 230 & 183 & 236 & 281 & 221 & 189 & 195 \\
\hline $\mathrm{X} 5$ & 252 & 186 & 131 & 237 & 289 & 157 & 180 & 178 \\
\hline $\mathrm{X} 6$ & 522 & 580 & 794 & 319 & 503 & 555 & 736 & 363 \\
\hline $\mathrm{X} 7$ & 501 & 648 & 694 & 290 & 523 & 700 & 727 & 365 \\
\hline $\mathrm{X} 8$ & 76 & 79 & 62 & 69 & 88 & 77 & 72 & 72 \\
\hline X9 & 92 & 70 & 67 & 106 & 98 & 96 & 64 & 71 \\
\hline $\mathrm{X} 10$ & 67 & 73 & 74 & 108 & 71 & 94 & 94 & 69 \\
\hline X11 & 25 & 97 & 82 & 29 & 26 & 19 & 25 & 25 \\
\hline $\mathrm{X} 12$ & 32 & 82 & 55 & 34 & 29 & 21 & 26 & 30 \\
\hline X13 & 76 & 15 & 255 & 115 & 68 & 108 & 185 & 102 \\
\hline X14 & 24 & 40 & 45 & 53 & 26 & 68 & 43 & 54 \\
\hline $\mathrm{X} 15$ & 82 & 63 & 107 & 48 & 63 & 94 & 61 & 66 \\
\hline X16 & 91 & 29 & 117 & 58 & 46 & 61 & 82 & 86 \\
\hline $\mathrm{X} 17$ & 92 & 79 & 306 & 90 & 81 & 109 & 140 & 74 \\
\hline
\end{tabular}




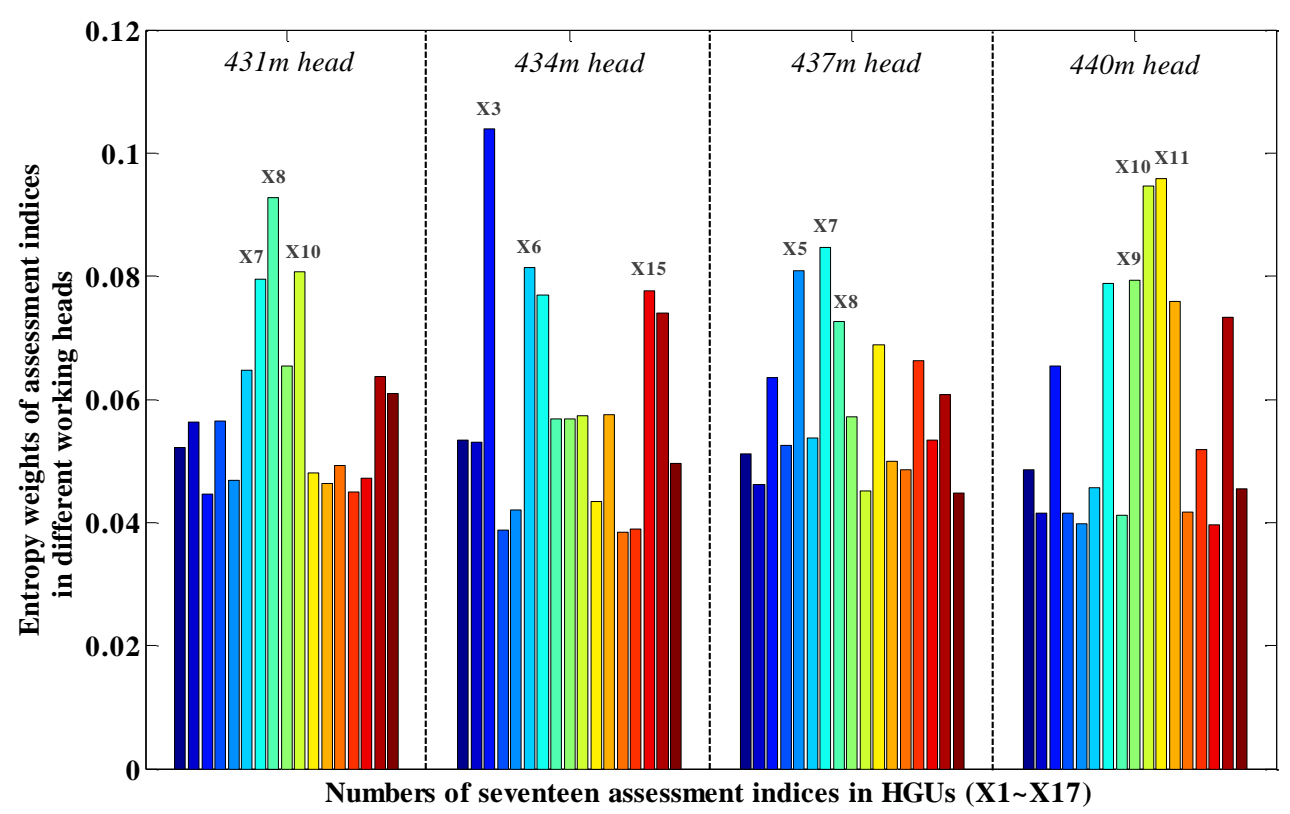

355 Fig. 9 Entropy weights of seventeen assessment indices for four on-load HGUs with different working heads
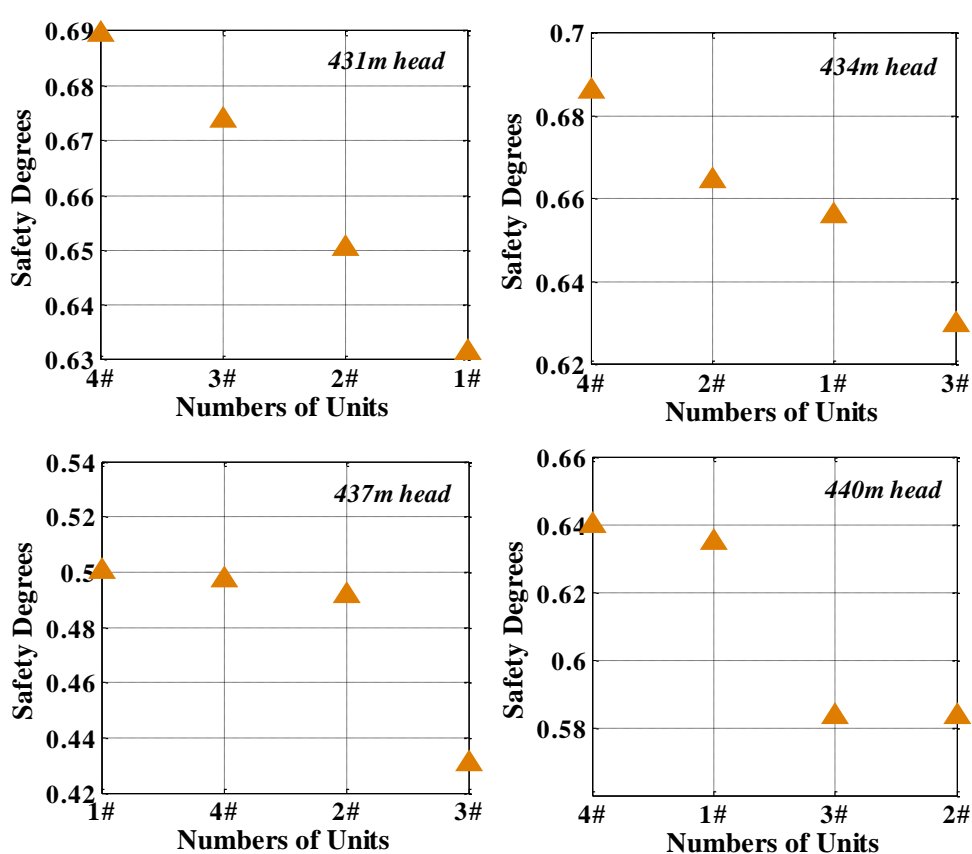

Fig. 10 Estimated safety levels of four on-load HGUs operating with different working heads at 
Fig. 9 indicates the assessment weights (i.e. the calculated entropy weights in Eq. (3))

361 of seventeen indices for HGUs operating with working heads of $431 \mathrm{~m}, 434 \mathrm{~m}, 437 \mathrm{~m}$ and

$362440 \mathrm{~m}$. It should be noted that the same index assessed in different allowable heads has

363 the same color. Considering Fig. 9, it is observed that the weight of each index differs

364 considerably as the allowable head changes. This confirms the sensitivity of assessment

365 indices on the HGUs' working heads as well as the fact that the information associated

366 with the indices for the studied units is not identical. For instance, the highest weights for

$367431 \mathrm{~m}$ working head are estimated as 0.093 for the horizontal vibration of upper bracket in

$368 \mathrm{X}$ direction (X8 index), 0.081 for the vibration of upper bracket in $\mathrm{Z}$ direction (X10 index)

369 and 0.08 for the swing of hydraulic guide bearing in Y direction (X7 index). Similarly, it

370 is found that for the HGU with $434 \mathrm{~m}$ working head, the main indices are X3, X6 and X15;

371 for the $437 \mathrm{~m}$ head unit, the main indices are X7, X5 and X8; and for the 440m head, they

372 are X11, X10 and X9. Based on the effect of main indices and experimental results, the

373 safety issues in the units with working heads of $431 \mathrm{~m}, 434 \mathrm{~m}$ and $437 \mathrm{~m}$ may be caused by

374 the integrating effect of mechanical problems and hydraulic imbalance while the

375 mechanical component only results in a slight vibration of the units operating with the

$376440 \mathrm{~m}$ head. It should also be noted that all assessment indices influence the safety of each

377 unit although their contributions may vary significantly in different working heads.

378 Fig. 10 presents the estimated safety degree of the four HGUs under different 379 working heads. The probabilistic results indicate that the most stable HGU is unit 4 with 380 the average safety degree of 0.6282 . Unit 1 is the second most stable unit with the 
average safety degree of 0.6057 . Unit 2 is the third safest unit of the four with the average safety degree of 0.5974 while unit 3 has the highest operational risk with its average safety degree of 0.5793 . Based on the results, the system can safely run in the orders suggested in Fig. 10 when the allowable head fluctuates around 431m, 434m, 437m and $440 \mathrm{~m}$. However, when the hydropower station is not able to predict the working head of HGUs in advance, it is suggested that the optimal operational schedule is as follows: unit 4, unit 1 , unit 2 and unit 3. This provides the safe operating strategy of HGUs to cope with peaks and troughs of electricity demand within the station.

It is also observed, in Fig. 10 that the safety degree of four units for the allowable head of $437 \mathrm{~m}$ is lower than other working heads, changing between the range of $[0.4305$, 0.5004]. That is, the average safety of HUGs is less than 50 percent under the allowable head of $437 \mathrm{~m}$. It can therefore be a reasonable suggestion that the HGUs at the studied station could avoid, if possible, operating with this condition to enhance the operational safety.

\section{Conclusions}

In this paper, a new framework is presented for the safety assessment of HGUs in hydropower stations and addresses the limitations in this research field. The study is carried out based on four on-load HGUs operating at an existing hydropower station in China. A dynamic balance experiment of the units with different allowable heads is conducted to qualitatively investigate the system stability and to obtain the requirements 
402 for further quantitative analyses. This was performed by using the grey correlation 403 analysis and entropy weights method. It is demonstrated that there is a significant 404 difference in the sensitivity and risk contribution of the adopted indices between the 405 allowable heads of $431 \mathrm{~m}, 434 \mathrm{~m}, 437 \mathrm{~m}$ and $440 \mathrm{~m}$. The measurements of the weights 406 reveal that, the safety of units operating with a head of $431 \mathrm{~m}, 434 \mathrm{~m}, 437 \mathrm{~m}$ depend on the 407 combined contribution of mechanical issues and hydraulic imbalance, while the undesired 408 events occurring for units with $440 \mathrm{~m}$ of head may only be caused by mechanical issues.

409 From the grey-entropy assessment results, it can be concluded that the units have their 410 specific safety degree as the allowable head changes. Moreover, a safe operational 411 schedule can follow the order of: unit 4, unit 1, unit 2 and unit 3 . It is anticipated that the 412 proposed method can be adopted for improving the safety of hydropower facilities by 413 providing optimal operational schedules.

\section{Appendix}

\section{Numerical process of the safety degree in HGUs}

417 The aim of the numerical analysis is to establish the grey-entropy correlation degree 418 (see Eq. (7)) to conduct a dynamic safety assessment of on-load HGUs. Eq. (7) is combined 419 with the entropy weights (see Eq. (3)) and the grey correlation coefficients (see Eq. (4)). 420 That is, the numerical analysis consists of three steps to obtain the dynamic safety degree of 421 HGUs: i) based on the measurement data of seventeen indices in Table 4, we calculate the 
422 entropy weight matrix of index $\boldsymbol{W}_{\boldsymbol{i}}$ with respect to different working heads, ii) estimating

423 the correlation coefficient matrix of indices $\xi_{i}(j)$ for different working heads based on the

424 grey correlation equations (see Eqs. (4) to (6)) and iii) substituting the entropy weight

425 matrix $W_{i}$ and correlation coefficient matrix $\xi_{i}(j)$ into the grey-entropy correlation

426 degree (see Eq. (7)). Finally, the dynamic safety degree matrix of studied HGUs $\boldsymbol{\alpha}_{i}$ under

427 different working heads is obtained. A detailed calculation progress is performed as

428 follows.

429 In this study, we have seventeen assessment indices (marked as $j$ ) and four HGUs

430 (marked as $i$ ) operating with four working heads of $431 \mathrm{~m}, 434 \mathrm{~m}, 437 \mathrm{~m}$ and $440 \mathrm{~m}$. The

431 optimum safety matrix is [0], and the assessment matrices of the four HGUs at different

432 working heads, i.e. $\left[\boldsymbol{r}_{i j}\right]_{431 \mathrm{~m}},\left[\boldsymbol{r}_{i j}\right]_{434 \mathrm{~m}},\left[\boldsymbol{r}_{i j}\right]_{437 \mathrm{~m}},\left[\boldsymbol{r}_{\boldsymbol{i j}}\right]_{440 \mathrm{~m}}$, are shown in Table 4 . The

433 normalized method of inverse index expressed in Eq. (1) is used to obtain the standard

434 form of optimum safety matrix and assessment matrices, which are

435

$[\mathbf{0}] \cap\left[\boldsymbol{r}_{i j}\right]_{431 \mathrm{~m}}=$

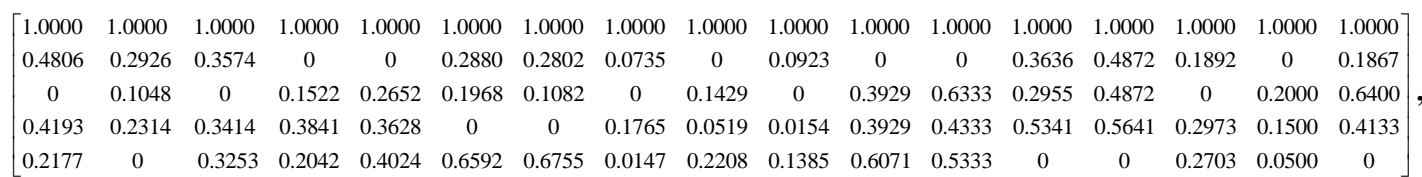

437

$[\mathbf{0}] \cap\left[\boldsymbol{r}_{i j}\right]_{434 \mathrm{~m}}=$

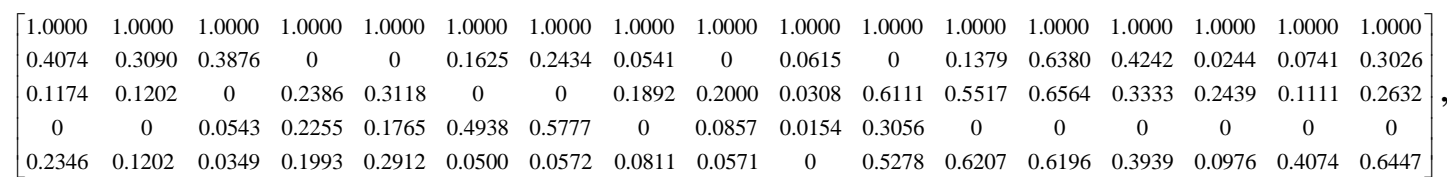




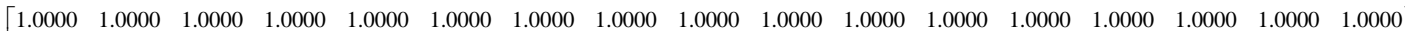
$\begin{array}{llllllllllllllllll}0.2683 & 0.3431 & 0.3411 & 0 & 0 & 0.3426 & 0.2781 & 0.0380 & 0.1321 & 0.3796 & 0.7423 & 0.6098 & 0.7020 & 0.5472 & 0.2336 & 0.2222 & 0.6993\end{array}$

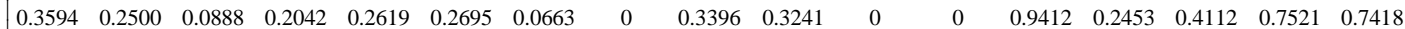
$\begin{array}{lllllllllllllllll}0 & 0.3284 & 0.2944 & 0.3668 & 0.4802 & 0 & 0 & 0.2152 & 0.3679 & 0.3148 & 0.1546 & 0.3293 & 0 & 0.1509 & 0 & 0 & 0\end{array}$

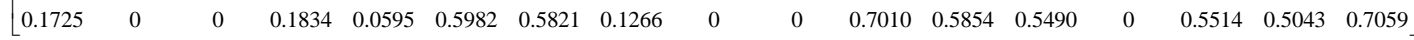

441 and

442

$[\mathbf{0}] \cap\left[\boldsymbol{r}_{i j}\right]_{440 \mathrm{~m}}=$

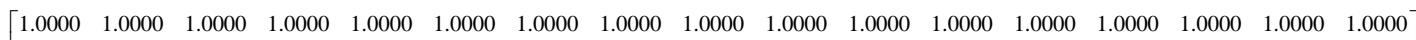

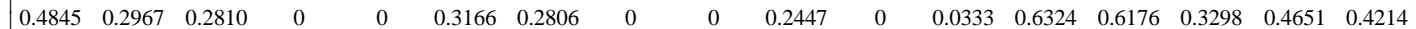

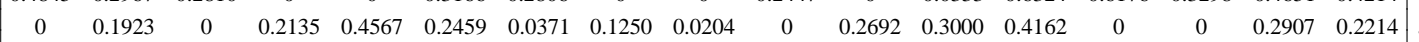

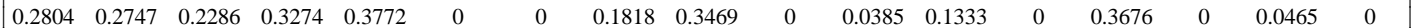

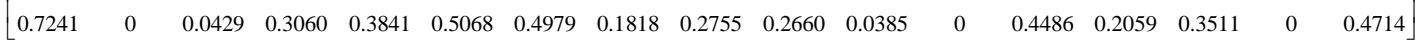

To clearly clarify the proposed method, an example for the assessment process of on-load HGUs at 440m working head is demonstrated as follows:

(i) Entropy weight matrix $\boldsymbol{W}_{i}$ : Based on Eq. (2) and (3), the entropy weight matrix of seventeen indices derived from assessment matrix $\left[\boldsymbol{r}_{i j}\right]_{440 \mathrm{~m}}$ is written as:

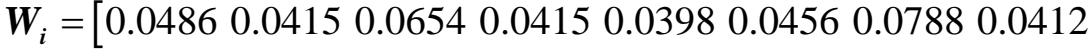

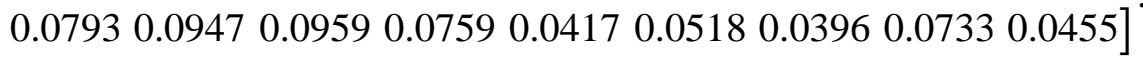

The minimum and maximum differences in the first level in Eq. (5) are obtained as:

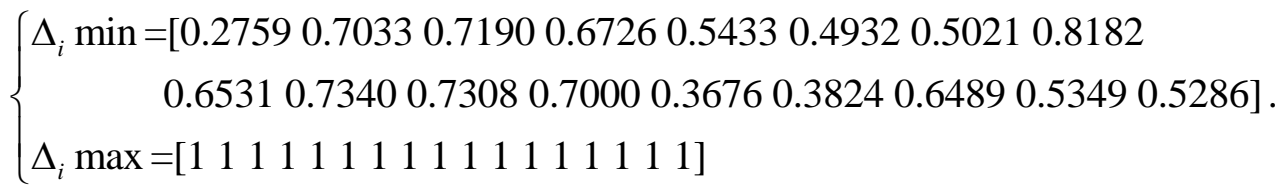

The minimum and maximum differences in the second level in Eq. (6) are obtained

$$
\left\{\begin{array}{l}
\min _{i}\left(\Delta_{i} \min \right)=0.2759 \\
\max _{i}\left(\Delta_{i} \max \right)=1
\end{array} .\right.
$$

We substitute the obtained values for $\Delta_{i} \min , \Delta_{i} \max , \min _{i}\left(\Delta_{i} \min \right)$ and 
457 with respect to the $j$ th factor in the index set $\left[r_{i j}\right]_{440 \mathrm{~m}}$ is estimated as:

$458 \quad \xi_{i}(j)=$

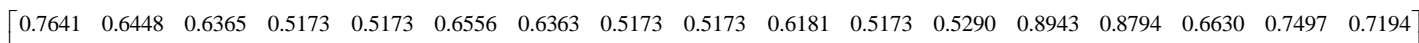
$\begin{array}{lllllllllllllllll}0.5173 & 0.5933 & 0.5173 & 0.6031 & 0.7437 & 0.6187 & 0.5304 & 0.5643 & 0.5244 & 0.5173 & 0.6304 & 0.6466 & 0.7159 & 0.5173 & 0.5173 & 0.6416 & 0.6068\end{array}$ $\begin{array}{llllllllllllllllllllll}0.6362 & 0.6332 & 0.6103 & 0.6617 & 0.6910 & 0.5173 & 0.5173 & 0.5886 & 0.6729 & 0.5173 & 0.5309 & 0.5677 & 0.5173 & 0.6852 & 0.6753 & 0.5338 & 0.5173\end{array}$ • $\left[\begin{array}{lllllllllllllllll}1.0000 & 0.5173 & 0.5325 & 0.6499 & 0.6953 & 0.7812 & 0.7743 & 0.5886 & 0.6337 & 0.6287 & 0.5309 & 0.5173 & 0.7380 & 0.5996 & 0.6454 & 0.5173 & 0.7543\end{array}\right]$

\section{(iii) Grey-entropy correlation degree (also called safety degree) $\alpha_{i_{-} 440 m}$ :}

The grey-entropy correlation degree, $\boldsymbol{\alpha}_{i}$, between the optimum unit and the studied

the working head of $431 \mathrm{~m}$ is

464

$$
\alpha_{i_{-} 440 m}=\left[\begin{array}{c}
0.6350 \\
0.5833 \\
0.5834 \\
0.6399
\end{array}\right], i=1,2,3 \text { and } 4 .
$$

466 head of $431 \mathrm{~m}, 434 \mathrm{~m}$ and $437 \mathrm{~m}$, respectively. The corresponding safety degree matrices

467 of the four HGUs are listed as follows:

$468431 \mathrm{~m}$ working head:

469

$$
\boldsymbol{\alpha}_{i_{-431 m}}=\left[\begin{array}{l}
0.6315 \\
0.6504 \\
0.6738 \\
0.6895
\end{array}\right], i=1,2,3 \text { and } 4 \text {. }
$$

$434 \mathrm{~m}$ working head: 
$472437 \mathrm{~m}$ working head:

$$
\boldsymbol{\alpha}_{i_{-} 437 m}=\left[\begin{array}{c}
0.5004 \\
0.4915 \\
0.4305 \\
0.4974
\end{array}\right], i=1,2,3 \text { and } 4 .
$$

\section{Acknowledgments}

476 This work was supported by the scientific research foundation of National Natural 477 Science Foundation of China--Outstanding Youth Foundation (No. 51622906), National 478 Natural Science Foundation of China (No. 51479173), Fundamental Research Funds for 479 the Central Universities (No. 201304030577), Scientific research funds of Northwest 480 A\&F University (No. 2013BSJJ095), Science Fund for Excellent Young Scholars from 481 Northwest A\&F University and Shaanxi Nova program (No. 2016KJXX-55).

\section{References}

484 [1] Sequeira TN, Santos MS. Renewable energy and politics: A systematic review and 485 new evidence. J Clean Prod 2018; 192: 553-568.

486 [2] Binama M, Su WT, Li XB, Li FC, Shi XZ, An S. Investigation on pump as turbine 487 (PAT) technical aspects for micro hydropower schemes: A state-of-the-art review. Renew $488 \quad$ Sust Energ Rev 2017; 79: 148-179. 
490 impacts associated with hydropower. Renew Sust Energ Rev 2017; 70: 896-904.

491 [4] Holanda PDS, Blanco CJC, Mesquita ALA, Brasil ACP, de Figueiredo NM, Macedo, 492 EN, Secretan Y. Assessment of hydrokinetic energy resources downstream of hydropower 493 plants. Renew Energy 2017; 101: 1203-1214.

494 [5] Yu X, Zhang J, Fan C, Chen S. Stability analysis of governor-turbine-hydraulic 495 system by state space method and graph theory. Energy 2016; 114: 613-22.

496 [6] Chang JX, Li YY, Yuan M, Wang YM. Efficiency evaluation of hydropower station 497 operation: A case study of Longyangxia station in the Yellow River, China. Energy 2017; $498 \quad 135: 23-31$.

499 [7] Li HH, Chen DY, Zhang H, Wu CZ, Wang XY. Hamiltonian analysis of a 500 hydro-energy generation system in the transient of sudden load increasing. Appl Energy $501 \quad 2017 ; 185: 244-253$.

502 [8] Aradag S, Akin H, Celebioglu K. CFD based design of a 4.3MW Francis turbine for 503 improved performance at design and off-design conditions. J Mech Sci Technol 2017; 31: $504 \quad 5041-5049$.

505 [9] Nasselqvist M, Gustavsson R, Aidanpaa JO. Bearing Load Measurement in a 506 Hydropower Unit Using Strain Gauges Installed Inside Pivot Pin. Exp Mech 2012; 52: $507 \quad 361-369$.

508 [10] Majidi M, Etezadi-Amoli M. Recapturing wasted energy in water pressure reducing 509 valves via in-conduit hydropower generators. Measurement 2018; 123: 62-68. 
510 [11] Li CS, Mao YF, Yang JD, Wang ZB, Xu YH. A nonlinear generalized predictive control for pumped storage unit. Renew Energ 2017; 114: 945-959.

[12] Xu BB, Chen DY, Tolo S, Patelli E, Jiang YL. Model validation and stochastic stability of a hydro-turbine governing system under hydraulic excitations. Int J Electr Power Energy Syst 2018; 95: 156-165.

[13] An XL, Pan LP, Zhang F. Analysis of hydropower unit vibration signals based on variational mode decomposition. J Vib Control 2017; 23: 1938-1953.

[14] Li RH, Li CS, Peng XL, Wei W. Electromagnetic vibration simulation of a 250-MW large hydropower generator with rotor eccentricity and rotor deformation. Energies 2017; 10: 2155 .

[15] Kishor N, Singh SP, Raghuvanshi AS. Dynamic simulations of hydro turbine and its state estimation based LQ control. Energy Conv Manag 2006; 47: 3119-3137. [16] $\mathrm{Xu}$
$\mathrm{BB}$, Chen
DY, Gao X, Tomas
C, Patelli
E. Dynamic evolution of a hydraulic-mechanical-electric system with randomly fluctuating speed. Nonlinear Dynam 2018; 92: 1801-1813.

[17] Zhang QF, Karney B, Suo LS, Colombo AF. Stochastic Analysis of Water Hammer and Applications in Reliability-Based Structural Design for Hydro Turbine Penstocks. J Hydraul Eng-ASCE 2011; 137: 1509-1521.

[18] Ferreira AR, Teegavarapu RSV. Optimal and adaptive operation of a hydropower system with unit commitment and water quality constraints. Water Resour Manag 2012; 26: 707-732. 
531 [19] Haguma D, Leconte R, Krau S. Hydropower plant adaptation strategies for climate 532 change impacts on hydrological regime. Can J Civ Eng 2017; 44: 962-970.

533 [20] Feng ZK, Niu WJ, Cheng CT, Wu XY. Optimization of hydropower system 534 operation by uniform dynamic programming for dimensionality reduction. Energy 2017; 535 134: 718-730.

536 [21] Sovacool BK, Walter G. Major hydropower states, sustainable development, and 537 energy security: Insights from a preliminary cross-comparative assessment. Energy 2018; 538 142: 1074-1082.

539 [22] Zou PXW, Lun P, Cipolla D, Mohamed S. Cloud-based safety information and 540 communication system in infrastructure construction. Safety Sci 2017; 98: 50-69.

541 [23] Guo K, Kuai X, Chen YY, Qi L, Zhang L, Liu YF. Risk assessment of land ecology 542 on a regional scale: Application of the relative risk model to the mining city of Daye, 543 China. Hum Ecol Risk Assess 2017; 23: 550-574.

544 [24] Abbassi R, Khan F, Garaniya V, Chai S, Chin C, Hossain KA. An integrated method 545 for human error probability assessment during the maintenance of offshore facilities. 546 Process Saf Environ Protect 2015; 94: 172-179.

547 [25] Arzaghi E, Abaei MM, Abbassi R, Garaniya V, Chin C, Khan F. Risk-based 548 maintenance planning of subsea pipelines through fatigue crack growth monitoring. Eng 549 Fail Anal 2017; 79: 928-939.

550 [26] Wang ZJ, Wang Q, Ai T. Comparative study on effects of binders and curing ages on 551 properties of cement emulsified asphalt mixture using gray correlation entropy analysis. 
Constr Build Mater 2014; 54: 615-622.

553 [27] Traversaro F, Redelico FO. Confidence intervals and hypothesis testing for the 554 Permutation Entropy with an application to epilepsy. Commun Nonlinear Sci Numer 555 Simul 2018; 57: 388-401.

556 [28] Xu XF, Qiao ZJ, Lei YG. Repetitive transient extraction for machinery fault 557 diagnosis using multiscale fractional order entropy infogram. Mech Syst Signal Proc $558 \quad 2018 ; 103: 312-326$.

559 [29] Sun GD, Guan X, Yi X, Zhou Z. Grey relational analysis between hesitant fuzzy sets 560 with applications to pattern recognition. Expert Syst Appl 2018; 92: 521-532.

561 [30] Cui W, Huang JY, Song HF, Xiao M. Development of two new anti-washout 562 grouting materials using multi-way ANOVA in conjunction with grey relational analysis. 563 Constr Build Mater 2017; 156: 184-198.

564 [31] Shaikh F, Ji Q, Shaikh PH, Mirjat NH, Uqaili MA. Forecasting China's natural gas 565 demand based on optimised nonlinear grey models. Energy 2017; 140: 941-951.

566 [32] Deng ZL, Lin WL, Li N, Han K, Hou YL, Zhang L. The uncertainty entropy of 567 low-rate speech quality evaluation and the analyses of the gray correlation. IEICE 568 Electron Express 2015; 12.

569 [33] Huang SC, Dao, TP. Multi-objective Optimal Design of a 2-DOF Flexure-Based 570 Mechanism Using Hybrid Approach of Grey-Taguchi Coupled Response Surface 571 Methodology and Entropy Measurement. Arab J Sci Eng 2016; 41: 5215-5231.

572 [34] Cai KF, Wang DF. Optimizing the design of automotive S-rail using grey relational 
573 analysis coupled with grey entropy measurement to improve crashworthiness. Struct 574 Multidiscip Optim 2017; 56: 1539-1553.

575 [35] You ML, Shu CM, Chen WT, Shyu ML. Analysis of cardinal grey relational grade 576 and grey entropy on achievement of air pollution reduction by evaluating air quality trend 577 in Japan. J Clean Prod 2017; 142: 3883-3889.

578 [36] Song W, Zhu JJ, Zhang ST, Chen Y. Decision Making Method for Dual Uncertain 579 Information based on Grey Incidence Analysis and Grey Relative Entropy Optimization. $580 \quad$ J Grey Syst 2017; 29: 78-98.

581 [37] Xu BB, Chen DY, Zhang H, Zhou R. Dynamic analysis and modeling of a novel 582 fractional-order hydro-turbine-generator unit. Nonlinear Dynam 2015; 81: 1263-1274.

583 [38] Trivedi C, Agnalt E, Dahlhaug OG. Investigations of unsteady pressure loading in a 584 Francis turbine during variable-speed operation. Renew Energ 2017; 113: 397-410.

585 [39] Huang SZ, Ming B, Huang Q, Leng GY, Hou BB. A Case Study on a Combination 586 NDVI Forecasting Model Based on the Entropy Weight Method. Water Resour Manag $587 \quad 2017 ; 31: 3667-3681$.

588 [40] Yuan ZC, Wu LJ, Yuan ZK, Li HW. Shape optimization of welded plate heat 589 exchangers based on grey correlation theory. Appl Therm Eng 2017; 123: 761-769.

590 [41] Feng YX, Hong ZX, Cheng J, Jia LK, Tan JR. Low Carbon-Oriented Optimal 591 Reliability Design with Interval Product Failure Analysis and Grey Correlation Analysis. 592 Sustainability $2017 ; 9$.

593 [42] Wang WP, Yang ZM, Lu Y, Sin YL, Zhang B. The Optimization Degree of Provincial 
594 Industrial Ecosystem and EKC of China-Based on the Grey Correlation Analysis. J Grey 595 Syst 2016; 28: 1-12.

596 [43] National standard of China (GB/T17189-2007). Code for field measurement of 597 vibrations and pulsation in hydraulic machines (turbines, storage pumps and 598 pump-turbines). China National Standardization Management Committee 2007.

599 [44] National standard of China (GB/T 15468-2006). Fundamental technical 600 requirements for hydraulic turbines. China National Standardization Management 601 Committee 2006.

602 